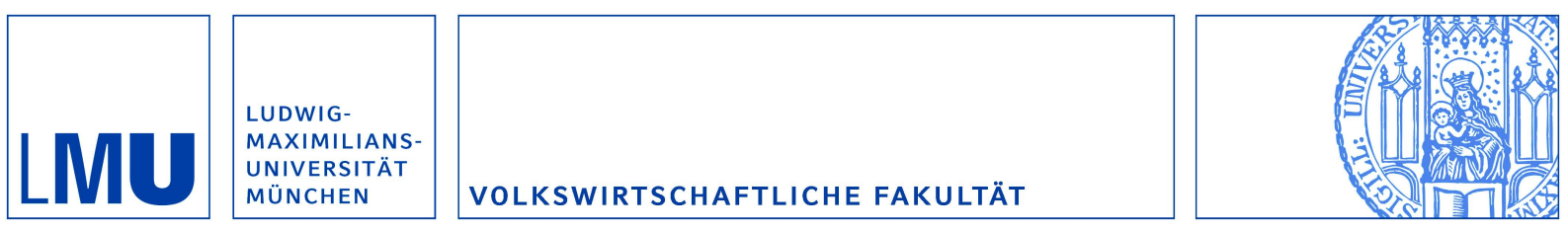

Schwardmann, Peter:

Motivated health risk denial and preventative health care investments

Munich Discussion Paper No. 2017-13

Department of Economics

University of Munich

Volkswirtschaftliche Fakultät

Ludwig-Maximilians-Universitäł München

Online at https://doi.org/10.5282/ubm/epub.38581 


\title{
Motivated health risk denial and preventative health care investments
}

\author{
Peter Schwardmann ${ }^{\dagger}$
}

May 2017

\begin{abstract}
People deny health risks, invest too little in disease prevention, and are highly sensitive to the price of preventative health care, especially in developing countries. Moreover, private sector R\&D spending on developing-country diseases is almost non-existent. To explain these empirical observations, I propose a model of motivated belief formation, in which an agent's decision to engage in health risk denial balances the psychological benefits of reduced anxiety with the physical cost of underprevention. I use the model to study firms' price-setting behaviour and incentive to innovate. I also show that tax-funded prevention subsidies are welfare enhancing.
\end{abstract}

Keywords: health risk denial, optimal expectations, motivated beliefs, disease prevention, self-protection JEL codes: D03, I15, I11, I18

\footnotetext{
${ }^{\dagger}$ University of Munich (LMU), Email: pschwardmann@gmail.com. I thank Roland Bénabou, Luc Bridet, Christian Gollier, Philipp Höfer, Iris Kesternich, Johannes Maier, Takeshi Murooka, Emily Oster, Frances Spies, Simeon Schudy, Paul Seabright, Ran Spiegler, Johannes Spinnewijn, Jean Tirole, Joël van der Weele and seminar participants at the University of Augsburg, the Free University of Brussels, the University of Munich, the Toulouse School of Economics, the EEA meeting in Mannheim and the EHEW in Hamburg for useful comments. I gratefully acknowledge financial support by the ERC through grant FP7/2007-2013 No. 249429, "Cognition and Decision-Making: Laws, Norms and Contracts", and by the Deutsche Forschungsgemeinschaft through CRC TRR 190.
} 
"There is potentially another reason the poor may hold on to beliefs that might seem indefensible: When there is little else they can do, hope becomes essential."

[Banerjee and Duflo, 2011]

\section{Introduction}

People cope with their anxiety about falling ill in two distinct ways. They either take preventative measures or deny the severity of the health risk they face. These two coping mechanisms are strategic substitutes. A person who takes sufficient precautions is likely to remain healthy and has no reason to be anxious and engage in denial. Conversely, a person who engages in denial about the health risks she is facing will deem preventative health care investments less essential. I formalise this tension between coping by investing in prevention and coping by denying reality in a simple model.

Consider an agent who experiences anxiety about contracting a disease in the form of anticipatory utility, as in Caplin and Leahy (2001). For her, optimism about health risks has the psychological benefit of reducing anxiety, but it carries the physical costs of bad decisions, because it will lead her to forgo some sensible investments in her health. Suppose that the agent chooses the belief that is optimal in light of this trade-off, as in Brunnermeier and Parker (2005) and Oster et al. (2013).

Choosing optimistic beliefs, or engaging in health risk denial, is more attractive to the agent if her ability to act is limited. A limited ability to act may be brought about by a low income, a lack of empowerment, or prevention technologies that are unavailable, expensive or ineffective. These factors keep the agent from taking action, leave her relatively exposed to health risks and therefore imply large psychological benefits from engaging in denial.

By decreasing the perceived value of preventative health care investments, motivated denial decreases the demand for prevention. It also makes demand more sensitive to the price and the effectiveness of the prevention technology. A price increase not only decreases demand through a standard price effect, but also increases the degree of optimism, which in turn further decreases demand. Demand is especially low and especially price-sensitive in resource-constrained settings, where, due to the agent's limited ability to act, motivated denial will be most severe. ${ }^{1}$

\footnotetext{
${ }^{1}$ Of course, underprevention in resource-constrained settings may be explained by several other factors, such as liquidity constraints, exogenous overoptimism, or impatience. However, as I show in appendix D, unlike motivated denial, these other impediments to demand generally imply demand that is less responsive to changes in the environment.
} 
A denialist's subjective health risk and her resulting valuation of a prevention technology are responsive to features of the market for preventative health care. Both subjective risk and valuation are higher in the low-price environment of perfect competition than under monopoly. However, because denialist consumers are more price-sensitive than rational consumers, a monopolist charges them lower prices. $^{2}$

Lower monopoly prices lead to lower profits, which in turn discourage R\&D spending on new prevention technologies, especially for developing-country diseases. The effect of motivated denial on a monopolist's incentive to invest in marginal improvements in the effectiveness of her product is more ambiguous. While the agent's lower demand level provides a disincentive, her higher demand sensitivity provides an incentive for the monopolist to invest. In resource-constrained settings, the former dominates and incentives for marginal innovations are blunted.

My model provides a unifying explanation of several findings in the empirical literature on health behaviour (see section 2.1 for a discussion). This literature documents optimistic beliefs about health risks, low and price-sensitive demand for prevention, and little investment by firms in R\&D. Moreover, these tendencies are generally found to be more pronounced in resource-constrained settings.

The model also yields an important policy implication. In the absence of health externalities, a rational agent's preventative efforts should never be subsidised, because her decision already optimally trades off the costs and benefits of investing in prevention. In contrast, for a denialist, a tax-funded prevention subsidy increases overall welfare, because it commits her to invest in prevention more frequently, thereby decreasing the physical cost associated with motivated denial.

This paper applies the motivated cognition framework (Akerlof and Dickens, 1982; Bénabou and Tirole, 2002; Brunnermeier and Parker, 2005) to the prevention of health risks. I follow the optimal expectations model (Brunnermeier and Parker, 2005; Oster et al., 2013) in assuming that beliefs are objects of choice. ${ }^{3}$ By imposing the structure of a prevention decision on the model, I am able to derive comparative statics that have distinct empirical counterparts. The paper's main contributions lie in demonstrating that motivated cognition can lead to behaviour that is highly sensitive to changes in the environment; in being the first to study the interaction of rational firms with denialist

\footnotetext{
${ }^{2}$ Denialists are not money pumps. Their behavioural trait actually decreases the material rent they have to transfer to a monopolist. This is because the denialist has access to a substitute good: the dream of a healthy life.

${ }^{3}$ I abstract from more elaborate models of belief manipulation, e.g. through information avoidance, biased recall, or self-signalling. My main results concern the question of why someone would want to hold biased beliefs (i.e. the demand for beliefs) and will be robust to different assumptions about how people arrive at them (i.e. the supply side).
} 
consumers; and in showing that motivated denial implies welfare gains from prevention subsidies.

The next section discusses the stylised empirical facts my model seeks to capture and reviews related papers in psychology and behavioural economics. I set the model up in section 3 and derive its main results in section 4. Section 5 features two extensions to the model. First, I analyse contexts in which, contrary to the baseline model, anxiety may induce the agent to invest in prevention. This allows me to ask when policy initiatives, such as the use of emotive warning labels, may backfire. Second, I follow Bénabou and Tirole (2002) by introducing present bias and the possibility of defensive pessimism into the model. Section 6 derives the paper's main policy result before section 7 concludes.

\section{Literature}

\subsection{Stylized empirical facts}

In this section I describe a number of empirical regularities that are consistent with my model of motivated health risk denial.

People are generally optimistic about health risks. Weinstein (1982) confronts a sample of college students with 45 different life-threatening hazards. For 34 of these hazards, students think that their risk is significantly below the average risk of their peers. In line with the idea that people have anticipatory utility concerns, unrealistic optimism decreases how much students worry. Overoptimism about health risks has been found in many subsequent studies. ${ }^{4}$ (Proposition 1).

Health risk denial is decreasing in an individual's ability and desire to act. Banerjee and Duflo (2011) cite several examples of misguided beliefs surrounding health care decisions in developing countries. They suggest that these are partly motivated by the poor's desire to remain hopeful when it is difficult to obtain effective and cheap health care. As I argue in appendix B, HIV/AIDS denial among women is negatively correlated with a country's female empowerment (controlling for education), indicating that those who are unable to protect themselves resort to optimism.

Oster et al. (2013) corroborate the optimal expectations model by Brunnermeier and Parker (2005) in a study of the health beliefs and economic behaviour of people at risk of Huntington disease. Individuals' propensity to engage in denial is decreasing in their

\footnotetext{
${ }^{4}$ See (Weinstein, 1987) for evidence from a representative sample of people from New Jersey. See Dunning et al. (2004) and Sandroni and Squintani (2004) for reviews of the literature.
} 
objective risk of having the disease, and, therefore, also decreasing in the costs associated with biased beliefs, like those stemming from suboptimal savings and retirement decisions.

In a seminal experiment, Kunda (1987) finds that female subjects who are heavy coffee drinkers are more likely to reject the validity of a study that links high caffeine consumption to an increased risk of cervical cancer than female subjects who drink little coffee. This may be explained by the greater cost the former group would incur in changing their behaviour if they took the study at face value. ${ }^{5}$ (Proposition 1 ).

\section{The demand for preventative health care in developing countries is extremely}

low. In a survey of health behaviour in developing countries, Dupas (2011) documents severe underinvestment in prevention. She cites the examples of malaria and diarrhoea, which each account for over 15 percent of under-five mortality in Sub-Saharan Africa, even though they could be effectively prevented by bed nets and point-of-use chlorination of drinking water. Yet the coverage of antimalarial bed nets and point-of-use water chlorination in the affected areas were each estimated to be under 10 percent (Miller et al., 2007; Stockman et al., 2007). While it is plausible that some prevention measures are simply not affordable for many people in poor countries, the high expenditures on curative health care in these settings both suggest that many people could in principle afford prevention and hint at its economic benefits.(Dupas, 2011). (Proposition 2).

Price effects on preventative health care investments are typically large. Dupas (2011) argues that developing-country prevention expenditures are very sensitive to price changes. For example, Cohen and Dupas (2010) and Kremer and Miguel (2007) find that moving from zero to positive prices that remain affordable to most potential customers decreases the take up of bed nets and deworming medication by 75 and 80 percent respectively. Ashraf et al. (2010) find rather price sensitive demand for a water treatment product in Zambia. Dupas (2011) concludes that both low demand and high price-sensitivity for preventative health care are surprising, given that the individual benefits of disease prevention appear to greatly outweigh the costs. (Proposition 3).

\section{Private $R \& D$ investment into preventative health care for developing-country} diseases is extremely low. Kremer (2002) documents that private R\&D investments into diseases that occur specifically in developing countries are almost non-existent. For example, Pecoul et al. (1999) find that, of the 1233 drugs that were licensed in the 22

\footnotetext{
${ }^{5}$ In the experiment, men serve as a control group that helps rule out alternative explanations. Their assessment of the study is not correlated with their coffee consumption because, by design, men were not threatened by the health condition in question.
} 
years before 1997, only 13 were aimed at tropical diseases. Limited R\&D is not surprising given the low demand in developing countries and the fact that pharmaceutical innovation is highly sensitive to market size (Acemoglu and Linn, 2004; Dubois et al., 2015). However, since demand may be very sensitive to the effectiveness of the prevention technology, limited innovation is also not a forgone conclusion. (Proposition 6 and corollary 2).

\section{$2.2 \quad$ Further related literature}

Several experimental studies in psychology suggest that people become overoptimistic (e.g. by means of self-deception, selective recall, biased updating, or biased information choice) because of a desire to feel good about themselves and less scared about their future. ${ }^{6}$ Kunda (1990) reviews this literature on motivated cognition and points out that its findings are broadly consistent with the somewhat more general theory of cognitive dissonance (Festinger, 1962). ${ }^{7}$

A small literature in experimental economics also documents that a person's beliefs are often responsive to the affective benefits of being more optimistic or confident. Mijović-Prelec and Prelec (2010) find that the incidence of self-deception in experimental subjects increases with the desirability of being self-deceived, as measured by the expected profits that accrue to a subject in the state of the world a self-deceiver deems more likely. 8 Mayraz (2011) and Coutts (2015) uncover similar self-serving optimism. In Eil and Rao (2011) and Mobius et al. (2011), subjects update signals in a way that leads to a more positive self-image. Focussing on a strategic motive for self-deception, Schwardmann and van der Weele (2016) show that experimental subjects become more overconfident in order to better convince others of their ability.

This paper is most closely related to a series of papers that model individuals who bias their beliefs in the service of psychological needs. ${ }^{9}$ Focussing applications that differ

\footnotetext{
${ }^{6}$ For example, in a famous experiment by Quattrone and Tversky (1984), subjects were told that the duration for which they could keep their arm submerged in ice water is indicative of their life expectancy. Those who were told that a long life expectancy corresponded to a long duration kept their arm submerged for substantially longer than those who were told that a short duration was indicative of a long life. Presumably, subjects tried to fool themselves into believing that they have a healthy life ahead of them.

${ }^{7}$ Cognitive dissonance arises when a person holds two conflicting beliefs or desires (e.g. the belief that she is at risk and a desire to feel safe). Moreover, people tend to strive for dissonance reduction (e.g. by changing their beliefs).

${ }^{8}$ Kocher et al. (2014) provide further evidence for positive anticipatory emotions, though there is no self-deception in their experiment.

${ }^{9}$ See Bénabou and Tirole (2016) for a recent survey of the nascent behavioural economics literature on motivated beliefs.
} 
from mine, Brunnermeier and Parker (2005), Brunnermeier et al. (2007) and Bénabou (2013), like me, emphasise an anticipatory utility motive for biased beliefs. The model in Akerlof and Dickens (1982) stresses the related motive of cognitive dissonance reduction. Kopczuk and Slemrod (2005) focus on people's fear of death, while the models in Carrillo and Mariotti (2000) and Bénabou and Tirole (2002) point to the motivational benefits of strategic ignorance and optimism.

Caplin and Leahy (2001), Caplin and Eliaz (2003), Kőszegi (2003) and Kószegi (2006) model anxiety as direct utility from beliefs, but do not equip their agents with the ability to choose their beliefs. Kőszegi (2003) studies an anxious individual's decision to go to the doctor and her choice of the doctor's quality. In Köszegi (2006), an informed agent transmits information to a principal with anticipatory utility concerns so as to maximise the principal's utility. Caplin and Eliaz (2003) analyse how to compel anxious individuals to get tested for HIV.

The implication of exogenously biased beliefs in market settings are investigated in de Meza and Southey (1996), Sandroni and Squintani (2007), Landier and Thesmar (2009), and Spinnewijn (2013).

\section{Model}

I study a risk-neutral individual with a three period time horizon: $t=1,2,3$. At $t=1$, she observes her true risk of infection, $\theta \in[0,1]$, and then chooses her belief or perceived risk, $\tilde{\theta} \in[0,1]$. Alternatively, we may think of an altruistic parent who knows $\theta$ and equips her child with belief $\tilde{\theta}$. Under a third interpretation, $\tilde{\theta}$ captures how much attention an individual pays to risk $\theta$.

At $t=2$, the agent chooses $x \in[0,1]$, her probability of investing in preventative health care. Investment entails costs $p+c$, where $p$ is a deterministic price paid to the seller of the prevention technology and $c$ captures the discomfort of the medical procedure, the difficulty of reaching a health facility, or the cost of exerting the willpower required to make the investment (e.g. the self-control required to abstain from risky sex). Cost $c$ is the $t=2$ realisation of a random variable $C$ that is uniformly distributed on the interval $[0, \bar{c}]$ and random from a $t=1$ perspective. ${ }^{10}$

Let $\alpha \in[0,1]$ denote the prevention technology's effectiveness, i.e. the probability, conditional on investing, that the technology offers protection. Then, the agent gets

\footnotetext{
${ }^{10}$ This assumption captures the inherent noisiness of future events. It assures that even a little optimism leads to a bad decision some of the time, and results in beliefs and demand that are continuous functions of the parameters. Assuming a uniform distribution greatly improves tractability.
} 


\begin{tabular}{llc}
\multicolumn{1}{c}{$t=1$} & \multicolumn{1}{c}{$t=2$} & $t=3$ \\
\hline - Observes true risk $\theta$ & $\bullet$ Cost $C \sim U[0, \bar{c}]$ is realised & $\bullet$ Physical payoffs $U_{3}$ : \\
- Belief choice $\tilde{\theta}$ & • Investment choice $x \in[0,1]$ & $V-x(c+p)$ if healthy \\
& • Anticipatory payoffs $s \mathbb{E}_{2}\left[U_{3}\right]$ & $V-L-x(c+p)$ if infected
\end{tabular}

Figure 1 Timing of the agent's actions and the realisation of payoffs

infected with probability $(1-\alpha) \theta$ if she invests and with probability $\theta$ if she fails to invest. At $t=3$, a healthy agent obtains physical payoffs of $V-x(p+c)$, whereas an infected individual suffers a loss of $L$, yielding payoffs of $V-L-x(p+c)$.

The agent's total utility is the weighted sum of $t=3$ physical payoffs and anticipatory payoffs, i.e. the agent's savouring, anxiety or dread. Let $\mathbb{E}_{t}$ and $U_{t}$ denote the agent's expectations and payoffs at $t$ and assume (for now) that there is no time-discounting. Then, the agent's objective at $t=1$ and $t=2$ can be written as

$$
\begin{array}{ll}
\text { Expected utility at } t=1: & \mathbb{E}_{1}\left[U_{3} \mid \theta\right]+s \mathbb{E}_{1}\left[\mathbb{E}_{2}\left[U_{3} \mid \tilde{\theta}\right]\right] \\
\text { Expected utility at } t=2: & \mathbb{E}_{2}\left[U_{3} \mid \tilde{\theta}\right]+s \mathbb{E}_{2}\left[U_{3} \mid \tilde{\theta}\right]
\end{array}
$$

where $s<1$ denotes the weight the agent places on anticipatory utility, i.e. her propensity to feel anxious or the salience of future outcomes. Anticipatory payoffs, the respective second terms in 1 and 2 , are utility flows from the agent's $t=2$ expectation of physical payoffs and are thus based on her perceived risk $\tilde{\theta}$. Physical payoffs, the respective first terms in 1 and 2 , are evaluated at the true risk, $\theta$, before the belief choice at $t=1$, but at possibly biased beliefs, $\tilde{\theta}$, thereafter. The timing of the agent's choices and payoffs is summarised in Figure 1.

At $t=2$, the agent finds it optimal to invest in prevention if and only if

$$
\begin{aligned}
(1+s) \mathbb{E}_{2}\left[U_{3}(x=1) \mid \tilde{\theta}\right] & \geq(1+s) \mathbb{E}_{2}\left[U_{3}(x=0) \mid \tilde{\theta}\right] \\
(1+s)(V-(1-\alpha) \tilde{\theta} L-c-p) & \geq(1+s)(V-\tilde{\theta} L)
\end{aligned}
$$

Assuming that she invests when she is indifferent between investing and not investing, 
her $t=2$ probability of investing is therefore given by

$$
\hat{x}(\tilde{\theta})= \begin{cases}1 & \text { if } \alpha \tilde{\theta} L \geq c+p \\ 0 & \text { otherwise }\end{cases}
$$

Consistent with the four core constructs in the health belief model (Janz and Becker, 1984), commonly used by psychologists to understand changes in health behaviour, investment or behavioural change is more likely when the the perceived susceptibility to a health problem (i.e. $\tilde{\theta}$ ) is high, when the perceived severity of a condition (i.e. $L$ ) is high, when the perceived benefits or the efficacy of engaging in a health-promoting behaviour (i.e. $\alpha$ ) is high, and when perceived barriers to taking action (i.e. $c+p$ ) are low. In my model, only the perceived susceptibility may differ from reality, but the model's insights readily translate to cases where other variables are subject to misperception or even directed belief manipulation.

At $t=1$, the agent chooses her belief $\tilde{\theta} \in[0,1]$ under consideration of the anticipatory benefits and the distorted investment decision it will induce. To eliminate uninteresting cases, I make the assumption that even a realistic agent does not always find it profitable to invest in prevention, i.e. $\alpha \theta L<\bar{c}+p$. The agent's $t=1$ expected utility is

$$
\begin{aligned}
\mathbb{E}_{1}\left[U_{3} \mid \theta\right]+s \mathbb{E}_{1}\left[\mathbb{E}_{2}\left[U_{3} \mid \tilde{\theta}\right]\right]= \\
\int_{0}^{\alpha \tilde{\theta} L-p}[V-(1-\alpha) \theta L-c-p] \frac{1}{\bar{c}} d c+\int_{\alpha \tilde{\theta} L-p}^{\bar{c}}[V-\theta L] \frac{1}{\bar{c}} d c \\
+s\left(\int_{0}^{\alpha \tilde{\theta} L-p}[V-(1-\alpha) \tilde{\theta} L-c-p] \frac{1}{\bar{c}} d c+\int_{\alpha \tilde{\theta} L-p}^{\bar{c}}[V-\tilde{\theta} L] \frac{1}{\bar{c}} d c\right)
\end{aligned}
$$

Because $c$ is random from the perspective of $t=1$, the agent forms an expectation over whether the realisation of $c$ induces investment. The first terms of each line in (4) express, respectively, the physical and anticipatory payoffs from investing in prevention weighted by the probability that investment occurs. The second terms express the expected payoffs for cost realisations that induce the agent to forgo investing in prevention. If the agent engages in denial, i.e. $\tilde{\theta}<\theta$, her anticipatory utility increases. However, gains in anticipatory utility come at the potential cost of impaired decision making, i.e. when an agent should invest in light of her objective risks, but fails to do so because she is optimistic. To see this, note that the physical payoffs, in the first line, are maximised at $\tilde{\theta}=\theta$.

I often refer to an individual's ability to act, which I define as follows. 
Definition 1. The agent's ability to act is low if the price, $p$, and the expected investment cost, $\bar{c} / 2$, are high and the effectiveness of the prevention technology, $\alpha$, is low.

In poor-country settings people often find their ability to act constrained, because prevention costs are high relative to their incomes (high $p$ and $\bar{c} / 2$ ), there are many drains on self-control and willpower (high $\bar{c} / 2$ ), and the effectiveness of prevention conditional on investing is limited by bad medical advice and a lack of empowerment (low $\alpha$ ). ${ }^{11}$ The expected loss conditional on not investing, $\theta L$, may be higher or lower in poor compared to rich settings: while the risk of contracting certain diseases is higher, the opportunity cost of contracting a disease, $L$, is likely to be depressed by a low life expectancy and a high general disease burden.

\section{Analysis}

\subsection{Optimal beliefs}

For now, I assume that the price $p$ is exogenously given. Therefore, I consider the effect of changes in the environment in the absence of strategic responses by the sellers of the prevention technology. This assumption fits the setting of most randomised controlled trials and speaks to the short-term effects of policy interventions as well as the general effects of interventions in domains void of markets. The agent's optimal belief is simply the perceived risk $\tilde{\theta}$ that maximises her $t=1$ expected utility in (4).

Proposition 1. The agent's optimal belief is

$$
\tilde{\theta}^{*}=\max \left[\frac{\theta}{1-s}-\frac{s(\bar{c}+\alpha p)}{(1-s) \alpha^{2} L}, 0\right] .
$$

It is weakly decreasing in i) the weight on anticipatory utility, $s$, ii) the price, $p$, and iii) the expected investment cost, $\bar{c} / 2$. It is weakly increasing in iv) the effectiveness of the prevention technology, $\alpha, v)$ the potential loss, $L$, and vi) the true risk of infection, $\theta$.

The model nests the rational baseline as a special case: when $s=0$, the optimal belief is realism, i.e. $\tilde{\theta}^{*}=\theta$. As in Brunnermeier and Parker (2005), when $s>0$, the agent always exhibits at least some optimism. Starting from $\tilde{\theta}^{*}=\theta$, slightly decreasing her belief entails physical costs that are of second order compared to the first order anticipatory benefits. Physical costs are small for modest optimism because mistakes occur infrequently (i.e. with probability $\alpha(\theta-\tilde{\theta}) L / \bar{c})$ and are small on average.

\footnotetext{
${ }^{11}$ See appendix B for a discussion of how a lack of empowerment maps into a low $\alpha$.
} 
The intuition behind comparative static $i$ is simple. The higher the relative weight on anticipatory emotions, the more the agent is willing to inflate them by lowering her perceived risk, while incurring the physical costs of underprevention. ${ }^{12}$ Results $i i$ and iii have the underlying intuition that, when the expected investment cost and price are high, the agent goes unprotected relatively often and the psychological benefits of underestimating the likelihood of infection are therefore large, i.e. there is a lot to be scared about. Result iv follows a similar logic. An ineffective prevention technology implies that investment occurs less frequently. And even if the agent invests in prevention, she may contract the disease with a high likelihood, which in turn implies a high psychological benefit from engaging in denial.

These results may be summarised as follows. Denial is decreasing in an individual's ability and desire to act on accurate information. We therefore expect denial to be more prevalent among less empowered groups, e.g. women in male-dominated societies, and among those who do not have access to cost-effective, state-of-the-art health care. In general, health risk denial is likely to be more pronounced in resourceconstrained, developing-country settings. In developed countries, the highest prevalence of misguided patient beliefs and the presence of quacks (i.e. fraudulent medical practitioners that facilitate denial) will be found for health conditions that do not allow for effective preventative measures or cures. Banerjee and Duflo (2011) cite the example of back pain.

According to results $v$ and $v i$, a higher $\operatorname{loss} L$ and a higher objective risk $\theta$ discipline the individual's desire to engage in denial. While both the physical costs and the psychological benefits associated with being more optimistic are increasing in $\theta$ and $L$, the assumption that $s<1$ implies that more weight is put on the costs.

Empirical work often elicits how stressed or anxious people feel about contracting a certain disease, rather than obtaining their assessment of objective risks. How anxious the agent is depends on how she expects to cope behaviourally (i.e. by exerting preventative effort) and on how she expects to cope psychologically (i.e. by denying or not focussing on the risk in question). In appendix C I derive a closed form solution for experienced anxiety and show that, paradoxically, motivated denial implies that the anxiety an individual experiences can be increasing in her ability to act.

\footnotetext{
${ }^{12}$ Note that this result need not hold when anxiety not only drives optimism, but also directly impacts upon an individual's propensity to invest in prevention. This scenario is explored in section 5.1 .
} 


\subsection{The demand for preventative health care}

\subsubsection{Motivated denial depresses demand}

The expected demand for preventative health care is given by the ex ante probability that the agent invests

$$
\begin{aligned}
D^{d} \equiv \mathbb{E}_{1}\left[\hat{x}\left(\tilde{\theta^{*}}\right)\right] & = \begin{cases}\int_{0}^{\alpha \theta^{*} L-p} \frac{1}{\bar{c}} d c & \text { if } \alpha^{2} \theta L-\alpha p>s \bar{c} \\
0 & \text { otherwise }\end{cases} \\
& = \begin{cases}\frac{\alpha \theta L-p}{(1-s) \bar{c}}-\frac{s}{(1-s) \alpha} & \text { if } \alpha^{2} \theta L-\alpha p>s \bar{c} \\
0 & \text { otherwise }\end{cases}
\end{aligned}
$$

where the superscript $d$ denotes the denialist, who is characterised by $s>0 .{ }^{13}$ By comparison, the ex ante probability that a realist, i.e. an agent with $s=0$, invests is given by

$$
D^{r} \equiv \mathbb{E}_{1}[\hat{x}(\theta)]= \begin{cases}\frac{\alpha \theta L-p}{\bar{c}} & \text { if } \alpha \theta L-p>0 \\ 0 & \text { otherwise }\end{cases}
$$

It is straightforward to see that the realist invests in prevention more often than the denialist. Intuitively, the more an individual is in denial, the less worthwhile she deems preventative efforts because, even in the absence of prevention, she feels relatively safe. In what follows, I often assume that demand is positive to facilitate analysing the comparative statics of the agent's demand.

Proposition 2. Suppose that $\alpha^{2} \theta L-\alpha p>s \bar{c}$, so that a denialist sometimes invests in prevention. Then the denialist's demand for preventative health care is lower than the realist's, i.e. $D^{r}>D^{d}$. Furthermore, the difference between a realist's and a denialist's demand, i.e. $D^{r}-D^{d}$, is increasing in the prevention technology's i) price, $p$, ii) expected investment cost, $\bar{c} / 2$, and iii) decreasing in its effectiveness, $\alpha$.

When we observe preventative efforts through the lens of a standard model and without observing beliefs, the demand for prevention may seem too low in light of the available prevention technology, the benefits of prevention and people's available budgets (e.g. as proxied for by what they are able to spend on treatment). And it will seem especially low in poor settings, which are characterised by a high $p$ and $\bar{c}$ relative to people's income, and a low $\alpha$.

\footnotetext{
${ }^{13} D^{d}$ is also the aggregate demand in a population with unit mass and random investment costs, but homogenous uniform cost distributions.
} 
When low demand coincides with an observation of misinformation or optimism, information campaigns may appear to be the appropriate policy intervention. However, the above propositions highlight that biased perceptions and underinvestment in prevention may have the same underlying cause: an agent's inability to act. As a consequence, information campaigns might be ineffective if the individual is not also empowered to take action.

\subsubsection{Motivated denial leads to more sensitive demand}

There are other explanations for the low demand for preventative health care in poor settings. Perhaps the most plausible of these are liquidity constraints, exogenous optimism, and impatience, i.e. the steep discounting of future utility streams. As I show in appendix D, these alternative explanations generally imply demand that is less responsive to changes in the environment. Motivated denial, on the other hand, can account for the highly sensitive demand that has been documented in empirical studies.

The agent's sensitivity of demand to a variable $z$, or her marginal demand, is simply the first derivative of demand in $z$. One agent's demand is more sensitive than another's to a variable $z$, if its first derivative is higher in the case of a positive first derivative and more negative in the case of a negative first derivative. The following proposition highlights that motivated denial leads to more sensitive demand.

Proposition 3. Suppose that $\alpha^{2} \theta L-\alpha p>s \bar{c}$, so that a denialist sometimes invests in prevention. Then the denialist's demand for preventative health care is more sensitive to changes in the environment than the realist's demand. Specifically, i) $\frac{d D^{d}}{d p}<\frac{d D^{r}}{d p}$, ii) $\frac{d D^{d}}{d \bar{c}}<\frac{d D^{r}}{d \bar{c}}$, and iii) $\frac{d D^{d}}{d \alpha}>\frac{d D^{r}}{d \alpha}$.

To understand the intuition behind the denialist's more sensitive demand, note that a change in price $p$, for example, impacts on demand in two ways: first, holding beliefs constant, a price reduction leads to higher demand through a standard price effect; second, by proposition 1 , beliefs become more realistic, which further increases demand. ${ }^{14}$

Proposition 3 implies that the likely returns to subsidies and improvements in the prevention technology may be underestimated through the lens of a rational model. Furthermore, the first three propositions suggests that the triple incidence of optimistic beliefs, low demand, and highly sensitive demand is consistent with motivated denial, especially if, as evidence suggests, it is more frequently observed in resource constrained

\footnotetext{
${ }^{14}$ It is easy to show that the denialist's demand elasticities are also more extreme than the realist's, where the denialist's and the realist's demand elasticity in a variable $z$ are defined as $\eta_{z}^{r} \equiv \frac{d D^{r}}{d z} \frac{z}{D^{r}}$ and $\eta_{z}^{d} \equiv \frac{d D^{d}}{d z} \frac{z}{D^{d}}$ respectively.
} 
settings. Of course, a more direct empirical test of the motivated denial framework would establish whether beliefs about unconditional risks vary with an individual's ability to act.

\subsection{The market for prevention technologies}

\subsubsection{Market outcomes}

Thus far, the price, $p$, was taken to be exogenous. Now consider a market setting, where $p$ is set strategically by a monopolist or competing firms. I assume that the timing in Figure 1 is modified as follows. At $t=0$, multiple firms post prices, or, in the case of monopoly, a single firm posts a price. Firms commit to their respective price and may not change it at $t=1$ or $t=2 .^{15}$

In setting their prices, firms only care about the shape of consumer demand and might well be agnostic about the behavioural bias behind the demand function. ${ }^{16}$ Firm $i$ maximises her $t=0$ expectation of $t=3$ profits

$$
\pi_{i}=p_{i} D^{d}\left(p_{i}\right)
$$

I therefore assume constant marginal costs and W.L.O.G. set them equal to zero.

Let the subscript $m$ denote monopoly outcomes. The following proposition characterises the market equilibrium in the case of a single firm.

Proposition 4. If $\alpha^{2} \theta L<s \bar{c}$, there is zero demand for the prevention technology at any price. If $\alpha^{2} \theta L>s \bar{c}$, a monopoly firm charges price $p_{m}^{*}=\frac{1}{2}\left(\alpha \theta L-\frac{s}{\alpha} \bar{c}\right)$ and thereby induces belief and demand

$$
\tilde{\theta}_{m}^{*}=\frac{(1-2 s) \theta}{2-2 s}-\frac{s(2-s) \bar{c}}{2(1-s) \alpha^{2} L}, \quad D_{m}^{*}=\frac{1}{2}\left(\frac{\alpha \theta L}{(1-s) \bar{c}}-\frac{s}{(1-s) \alpha}\right) .
$$

The monopolist responds to the agent's behavioural bias and the high price-sensitivity it induces by lowering prices. The equilibrium price is therefore lower the higher is $s$. The agent has a psychological substitute good at her disposal, which involves not purchasing the prevention technology and instead dreaming of a healthy future. To limit denial on behalf of the agent and keep the subjective valuation of the product up, the monopolist thus needs to give up a material rent in the form of a lower price.

\footnotetext{
${ }^{15}$ I solve for the subgame perfect equilibrium, with the natural adaptation that the consumer's beliefs are an object of choice.

${ }^{16}$ This is not to say that firms do not deploy marketing tools that explicitly target consumers' desire and ability to engage in denial, thereby affecting the shape of demand.
} 


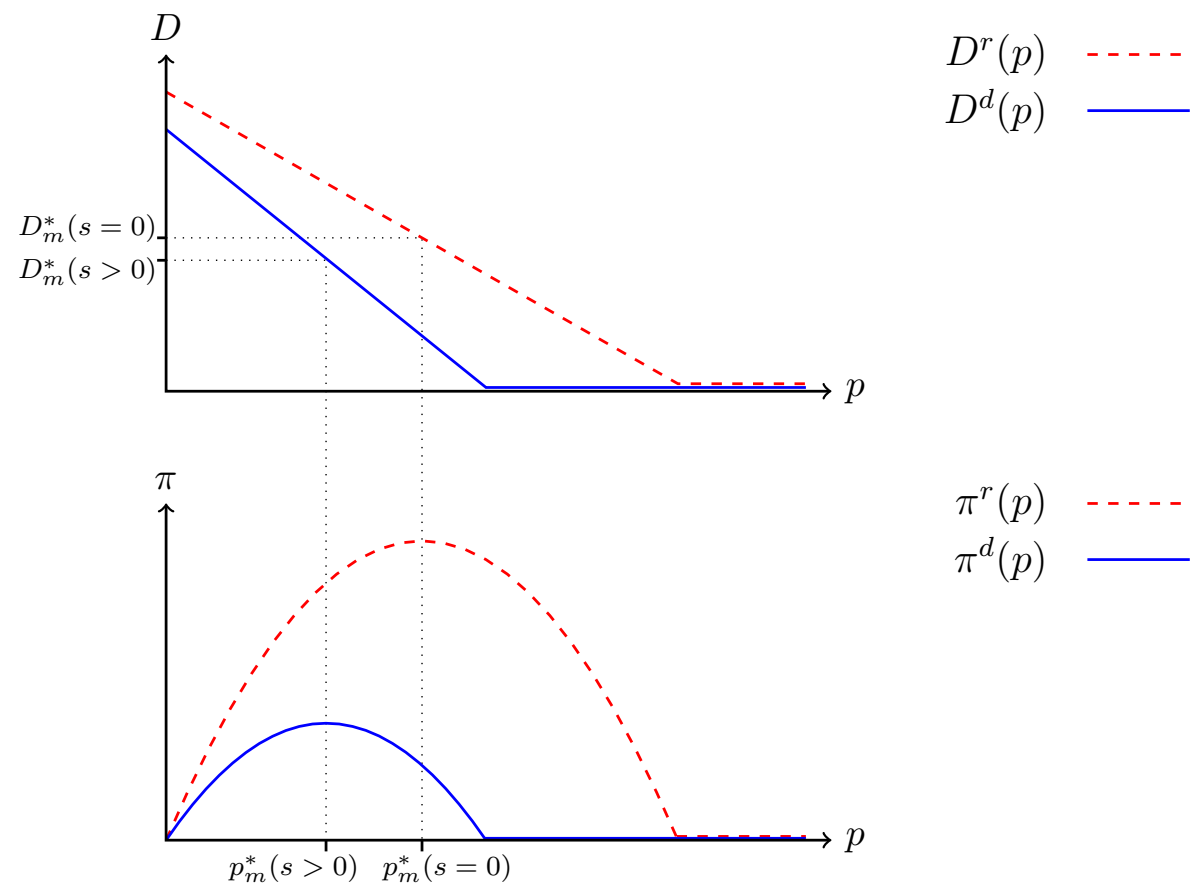

Figure 2 The denialist's and realist's demand for prevention (TOP) and respective monopoly profits (BOTTOM)

Figure 2 depicts the equilibrium allocation under monopoly. The denialist's demand curve is below the realist's and it is steeper. As a result, monopoly profits from selling to a denialist are lower everywhere and peak at a lower price.

When firms compete, I assume that, in the case of two or more firms posting the lowest price, they have an equal probability of selling to the agent. The following proposition then characterises the equilibrium when there is more than one firm posting prices at $t=0$ and firms' prevention technologies are perfect substitutes.

Proposition 5. If $\alpha^{2} \theta L<s \bar{c}$, there is zero demand at any price. If $\alpha^{2} \theta L>s \bar{c}$, the competitive equilibrium is characterised by the following price, belief and demand:

$$
p_{c}^{*}=0, \quad \tilde{\theta}_{c}^{*}=\frac{\theta}{1-s}-\frac{s \bar{c}}{(1-s) \alpha^{2} L}, \quad D_{c}^{*}=\frac{\alpha \theta L}{(1-s) \bar{c}}-\frac{s}{(1-s) \alpha} .
$$

Following a simple Bertrand logic, competition leads to marginal cost pricing. Propositions 4 and 5 tell us that we expect more consumer optimism in monopolistic settings. As market power gives rise to higher prices, consumers of the prevention technology find it more and more worthwhile to switch to their psychological substitute good, denial. Similarly, the agent's valuation of the good also depends on the market structure, with 
competition leading to higher valuations.

By comparing $D_{c}^{*}$ and $D_{m}^{*}$, we can crudely study the effect of competition, and thus competition policy, on the demand for prevention. Since we know from proposition 3 that an increase in $p$ has a disproportionally large impact on a denialist's demand compared to a realist's demand, we may expect motivated denial to provide a strong case for competition policy as a tool for increasing demand. The following corollary shows that the opposite is true, because the monopolist compensates for the demandreducing effect of denial by charging lower prices.

Corollary 1. Moving from monopoly to perfect competition brings about a smaller increase in demand when the consumer is a denialist rather than a realist, i.e. $D_{c}^{*}(s=$ $0)-D_{m}^{*}(s=0)>D_{m}^{*}(s>0)-D_{m}^{*}(s>0)$.

Since $p_{m}^{*}(s=0)>p_{m}^{*}(s>0)$ and $p_{c}^{*}(s=0)=p_{c}^{*}(s>0)=0$, corollary 1 also implies that the decrease in physical welfare a consumer experiences as the market for prevention becomes more monopolistic is smaller if she is a denialist $(s>0)$ rather than a realist $(s=0)$.

Since both the price a monopolist can charge and the demand she faces are decreasing in $s$, her profits also decrease in $s$. A monopolist would thus have an incentive to deploy any marketing tool that limits $s$ and, therefore, the agent's incentive to engage in denial. If she can, the monopolist will also try to hamper the agent's denial technology, i.e. decrease her ability to engage in denial. For example, this might be done by using persuasive advertisements and infomercials to frequently remind consumers of the risks they face. ${ }^{17}$

\subsubsection{Innovation}

Consider a firm's decision of whether to incur a fixed cost of $K$ to create a new prevention technology of effectiveness $\alpha$, for which it could then charge monopoly prices. This may be an HIV or Malaria vaccine, or a similar innovation that leapfrogs the current technology frontier to an extent that it affords substantial market power to its innovator.

\footnotetext{
${ }^{17}$ The monopolist cannot benefit from the behavioural aspects of the consumer's psychology because she is selling a product that becomes more desirable the more at risk an agent feels and she therefore cannot exploit consumer optimism. She would want to offer bets whose payoffs are contingent on the realisation of the consumer's health. Such bets could discipline the consumer's beliefs or, where this is more profitable, exploit them. However, the technical and legal difficulties involved in first verifying that someone is sick and then making them pay for it can probably account for the absence of such instruments in the market place for prevention. Of course, in other markets, instruments like this exist. For example, Bridet and Schwardmann (2016) show that in lending markets, collateral may be used to make a denialist pay for her optimism.
} 
It is easy to see from proposition 4 that both the price a monopolist charges and the resulting demand are decreasing in $s$. It follows that profits are also decreasing in $s$ and so is the size of the set of parameters for which monopoly profits are larger than a given fixed cost of innovation $K$.

Corollary 2. A firm's profit from developing a new prevention technology is decreasing in $s$. The difference between her profit if she faces a realist, i.e. $\pi_{m}(s=0)$, and her profit if she faces a denialist, i.e. $\pi_{m}(s>0)$, is increasing in $\bar{c}$ and $\alpha$.

Motivated denial therefore decreases firms' incentive to invent new products. Moreover, innovation is likely to be especially unprofitable in developing countries, where people's ability to act is limited and denial is most severe.

The model also allows me to speak about a monopolist's incentive to invest in marginal improvements to her product. Consider, for example, the decision of making existing malaria prophylaxis slightly more effective.

Proposition 6. A monopolist's marginal incentive to invest in improvements in the prevention technology, i.e. $\frac{d \pi_{m}}{d \alpha}$, is smaller for denialist than for realist consumers when $\alpha$ is small, i.e. $\alpha<\hat{\alpha}$, and larger for denialist than for realist consumers when $\alpha$ is large, i.e. $\alpha>\hat{\alpha}$, where threshold $\hat{\alpha}=\sqrt{\frac{s \bar{c}}{\theta L}}$.

As $s$ increases, demand becomes lower and more price-sensitive. The former effect decreases the marginal incentive to innovate while the latter increases it. When the agent's ability to act is limited (low $\alpha$ and high $\bar{c}$ ), the demand-level effect dominates and incentives to innovate are blunted by denialism. When the agent is more empowered to take action, the innovation-spurring effect of more sensitive demand dominates. The proposition implies little investment in marginal improvements to prevention technologies relevant to developing-country diseases and overly much investment in prevention technologies targeting rich-country diseases.

\section{$5 \quad$ Extensions}

\subsection{Anxiety-driven health investments}

In the baseline model, I assume that all benefits and costs are obtained at $t=3$. Instead, suppose that the investment cost $x(c+p)$ is incurred at $t=2$ and that the agent's anticipatory payoffs do not depend on them directly.

For example, consider the decision to practice safe sex. The main cost may stem from exerting self-control at $t=2$. But although resisting temptation is difficult, exerting 
the $t=2$ effort may not make the agent feel any worse at $t=3$. Then, someone with a higher propensity to feel anxious $s$, puts more weight on $t=3$ payoffs relative to $t=2$ costs, which in turn may make her more likely to invest.

Such anxiety-driven investments in prevention are likely to be more prevalent where the investment cost mostly consists of effort, as in the case of abstaining from risky sex, exercising more, or obtaining (free) HIV mother to child transmission prevention from a far away clinic. The baseline model is probably more pertinent to financially expensive preventative or diagnostic measures. Of course, many prevention technologies are expensive relative to low incomes in developing countries. In the developed world, CAT scans are an example of the baseline model's assumption. Also captured by the baseline model are preventative technologies that exacerbate the adverse consequences of being infected even though they lower the probability of infection, e.g. malaria prophylaxis.

Figure 3 depicts the new timing. It yields the following objectives.

$$
\begin{array}{ll}
\text { Expected utility at } t=1: & \mathbb{E}_{1}\left[U_{3}-x(c+p) \mid \theta\right]+s \mathbb{E}_{1}\left[\mathbb{E}_{2}\left[U_{3} \mid \tilde{\theta}\right]\right] \\
\text { Expected utility at } t=2: & \mathbb{E}_{2}\left[U_{3}-x(c+p) \mid \tilde{\theta}\right]+s \mathbb{E}_{2}\left[U_{3} \mid \tilde{\theta}\right]
\end{array}
$$

where $U_{3}$ no longer includes the investment cost. The agent now invests if $(1+s) \alpha \tilde{\theta} L \geq$ $c+p$. So that, holding $\tilde{\theta}$ constant, innate anxiety $s$ has a direct positive effect on investment. However, since $\tilde{\theta}$ is still decreasing in $s$, the total effect of an increase in $s$ on the demand for health care is ambiguous. In the baseline model, an increase in $s$ brings about an unambiguous decrease in the demand for prevention. I again assume that price $p$ is exogenously given. Then the following proposition pins down the effect of a change of $s$ in the augmented model. ${ }^{18}$

Proposition 7. The demand for prevention is weakly increasing in $s$ if $2 \alpha^{2} \theta L>\bar{c}+\alpha p$, and weakly decreasing in $s$ if $2 \alpha^{2} \theta L<\bar{c}+\alpha p$.

The success of policy measures that aim to raise $s$, for example, by increasing the salience of adverse outcomes, thus crucially depends on the environment. In affluent settings with a well functioning health sector, or for conditions for which there exists a sufficiently effective and cheap prevention technology (i.e. high $\alpha$ and low $\bar{c}$ and $p$ ), a higher innate anxiety or salience of future outcomes may lead to more prevention. In these settings, a policy maker may thus seek to increase $s$ by means of infomercials or

\footnotetext{
${ }^{18}$ The other main predictions of the baseline model do not change qualitatively once we allow for the timing in Figure 3.
} 


\begin{tabular}{lll}
\multicolumn{1}{c}{$t=1$} & \multicolumn{1}{c}{$t=2$} & \multicolumn{1}{c}{$t=3$} \\
\hline$\bullet$ Observes true risk $\theta$ & $\bullet$ Cost $C \sim U[0, \bar{c}]$ is realised & $\bullet$ Physical payoffs $U_{3}:$ \\
• Belief choice $\tilde{\theta}$ & $\bullet$ Investment choice $x \in[0,1]$ & $V$ if healthy \\
& $\bullet$ Incurs cost $\mathrm{x}(\mathrm{c}+\mathrm{p})$ & $V-L$ if infected \\
& $\bullet$ Anticipatory payoffs $s \mathbb{E}_{2}\left[U_{3}\right]$ & \\
Knows $\theta$ &
\end{tabular}

Figure 3 Timing of the agent's actions and the realisation of payoffs in the case of anxiety-driven health investments

warning labels on harmful products.

However, while such scare tactics may work in rich country settings, where individuals are truly empowered to take action, they can be counterproductive in poor settings. Policy makers should therefore be weary of exporting successful health marketing from developed- to developing-country contexts, where they might backfire.

Similarly, warning labels on alcohol and cigarettes may decrease consumption and increase cessation for moderate smokers and drinkers, but lead to an increase of denial and consumption for addicts and heavy users, for whom the costs of cessation are very high. The model may thus help understand where and why there are boomerang effects to warning labels on harmful products (see Robinson and Killen, 1997 and Ringold, 2002).

\subsection{Defensive pessimism}

Suppose that the agent is present biased. At $t$ she applies a discount factor $\beta<1$ to any payoff at $t+i$, with $i=1,2$. For present bias to matter, it is important that investment costs are incurred before the benefits from investing are realised. I therefore adopt the timing in Figure 3. The agent's objectives at $t=1$ and $t=2$ are given by

$$
\begin{array}{ll}
\text { Expected utility at } t=1: & \beta\left(\mathbb{E}_{1}\left[U_{3}-x(c+p) \mid \theta\right]+s \mathbb{E}_{1}\left[\mathbb{E}_{2}\left[U_{3} \mid \tilde{\theta}\right]\right]\right) \\
\text { Expected utility at } t=2: & \beta \mathbb{E}_{2}\left[U_{3} \mid \tilde{\theta}\right]-x(c+p)+s \mathbb{E}_{2}\left[U_{3} \mid \tilde{\theta}\right]
\end{array}
$$

At $t=2$, the agent only invests if $(1+s) \beta \alpha \tilde{\theta} L \geq c+p$. This introduces a new conflict of interest between the agent's self at $t=1$ and her self at $t=2$. Even at realistic beliefs $\tilde{\theta}=\theta$, the agent invests less frequently than would be materially optimal from her $t=1$ perspective, which would have her invest whenever $(1+s) \beta \alpha \tilde{\theta} L \geq \beta(c+p)$.

As suggested by Bénabou and Tirole (2002), the agent can overcome her self-control 
bias by manipulating her beliefs. In particular, the pessimistic belief $\tilde{\theta}=\theta / \beta$ can restore material efficiency. Ultimately, the agent's chosen belief optimally trades off the selfcontrol and the anticipatory benefits of biased beliefs. Focussing on the case where price $p$ is exogenous and present bias is not too severe $\beta>0.5,{ }^{19} \mathrm{I}$ arrive at the following proposition.

Proposition 8. The agent's optimal belief is given by

$$
\tilde{\theta}_{\beta}^{*}=\max \left[\frac{\theta}{\beta(1+s)^{2}-2 s}-\frac{s(\bar{c}+\alpha p)}{(1+s)\left(\beta(1+s)^{2}-2 s\right) \beta \alpha^{2} L}, 0\right] .
$$

When $\beta=1$, the optimal belief naturally coincides with the optimal belief in proposition 1 , and even when $\beta<1$, the comparative statics, other than in $s$, are the same as in proposition 1. It is easy to see that when $s$ is small, the self-control motive dominates and the individuals perceived risk exceeds the objective risk, compelling her to invest more often. Moreover, such defensive pessimism is more likely when $\bar{c}$ and $p$ are low and $\alpha$ is high. As in the baseline model, a limited ability to act leads to more optimistic beliefs. However, in the presence of self-control problems, a qualitative difference between health attitudes in poor and rich settings may arise. The extended model is consistent with pessimistic beliefs in rich countries and optimism in developing countries.

\section{$6 \quad$ Policy implications}

Consider a policy maker who attaches the same weight to the agent's anticipatory emotions as the agent's $t=1$ self and who therefore seeks to maximise a weighted sum of physical and psychological payoffs. This is in the spirit of Caplin and Eliaz (2003) who write that

Psychological realities of this type need no longer be seen as barriers to progress in economic theory. Rather, they are profoundly enriching. The time has come not only to acknowledge their importance, but also to incorporate them into policy analysis.

Suppose the policy maker chooses a subsidy $\sigma$ and a lump-sum tax $T$ to fund the subsidy. The subsidy is paid out to the agent if and only if the agent invests in prevention. Taxation does not entail a deadweight loss.

The agent's actions proceed as in the timing in Figure 1. At an additional initial stage, at $t=0$, the policy maker commits to a policy pair $(\sigma, T)$. Suppose that $p$ is once

\footnotetext{
${ }^{19}$ The latter assumption assures an interior solution, but is not necessary to solve the problem.
} 
again fixed. The policy maker's objective function and the agent's $t=1$ utility under subsidy and lump-sum tax coincide. This objective function is given by

$$
\begin{aligned}
& W=\mathbb{E}_{1}\left[U_{3} \mid \theta\right]+s \mathbb{E}_{1}\left[\mathbb{E}_{2}\left[U_{3} \mid \tilde{\theta}\right]\right]= \\
& \quad \int_{0}^{\alpha \tilde{\theta} L-p+\sigma}[V-(1-\alpha) \theta L-c-p+\sigma] \frac{1}{\bar{c}} d c+\int_{\alpha \tilde{\theta} L-p+\sigma}^{\bar{c}}[V-\theta L] \frac{1}{\bar{c}} d c \\
& +s\left(\int_{0}^{\alpha \tilde{\theta} L-p+\sigma}[V-(1-\alpha) \tilde{\theta} L-c-p+\sigma] \frac{1}{\bar{c}} d c+\int_{\alpha \tilde{\theta} L-p+\sigma}^{\bar{c}}[V-\tilde{\theta} L] \frac{1}{\bar{c}} d c\right) \\
& -(1+s) T
\end{aligned}
$$

The tax $T$ reduces the agent's material as well as her psychological payoffs. ${ }^{20}$ Because of the policy maker's ability to commit to the tax at $t=0$, the agent's belief choice does not depend on $T$.

I assume that the policy maker balances her budget in expectation, i.e. $T=$ $\int_{0}^{\alpha \tilde{\theta} L-p+\sigma} \sigma \frac{1}{\bar{c}} d c$. Then, let $\left(\tilde{\theta}^{*}, \sigma^{*}, T^{*}\right)$ denote the policy equilibrium. It satisfies

$$
\begin{aligned}
\tilde{\theta}^{*} & =\underset{\tilde{\theta}}{\operatorname{argmax}} \quad W\left(\tilde{\theta}, \sigma^{*}\right) \\
\sigma^{*}, T^{*} & =\underset{\sigma, T}{\operatorname{argmax}} \quad W\left(\tilde{\theta}^{*}, \sigma, T\right), \quad \text { s.t. } \quad T=\int_{0}^{\alpha \tilde{\theta}^{*} L-p+\sigma} \sigma \frac{1}{\bar{c}} d c
\end{aligned}
$$

In equilibrium, the agent chooses the optimal belief in response to the tax-subsidy pair chosen by the policy maker. The policy maker chooses the optimal subsidy and tax under a balanced budget and in light of the beliefs a given policy will induce.

Proposition 9. Suppose that $\alpha^{2} \theta L-\alpha p>s \bar{c}$, so that a denialist sometimes invests in prevention in the absence of any subsidy. Then the equilibrium subsidy is given by

$$
\sigma^{*}=\frac{s\left(\bar{c}+\alpha p-\alpha^{2} \theta L\right)}{\alpha(1+2 s)} \geq 0 .
$$

The optimal subsidy is zero when the agent has no anticipatory utility concerns and positive in the presence of the psychological motive. In the rational baseline, with $\mathrm{s}=0$, the agent chooses the investment decision that is materially optimal on the basis of objective beliefs. Any subsidy would only distort behaviour and cause inefficiencies.

In the presence of motivated denial, a tax-funded subsidy improves welfare. Recall that the physical costs of motivated denial stem from the agent's systematic tendency to

\footnotetext{
${ }^{20}$ Other things equal, paying the tax implies lower consumption at $t=3$ and, therefore, the agent also anticipates lower consumption.
} 
underinvest due to her overly optimistic $t=2$ beliefs. Assuming beliefs do not change, a subsidy increases $t=2$ investment and can therefore partially correct for this mistake. ${ }^{21}$ Welfare then improves further because beliefs are optimally adjusted to the presence of the subsidy.

A similar welfare gain could also be achieved by a mandatory insurance for prevention expenditures. Suppose that at $t=0$ the agent pays a premium $T$ to an insurance company who commits to cover her prevention costs up to $\sigma$. Further assume that the competitive insurer needs to break even in expectation. Then proposition 9 captures the equilibrium insurance contract. The model may thus help explain why insurance premia are often funding preventative health care investments. Insurance provides a way for the agent to commit to better prevention decisions. Note that this motive is absent in standard models of insurance.

I make the assumption that $p$ is fixed. Naturally, when the producer of the prevention technology has market power, she will increase prices in response to a subsidy and thereby erode the subsidy's effectiveness. Policy makers therefore need to pay heed to the market structure and effective subsidies may require concurrent price regulation.

Positive subsidies are also optimal under a different specification of the policy maker's objective function. Consider a policy maker who puts no weight on the agent's anticipatory utility and is concerned only with maximising physical payoffs. Since investment is inefficiently low from the perspective of physical payoffs, a subsidy can restore physical efficiency by increasing investment.

Since optimal beliefs are decreasing in price, a subsidy leads to more realistic beliefs. However, not all forms of paternalism lead to less denial. A subsidy reduces denial only because it ultimately still requires the agent to make the investment decision. Instead, forcing the agent to invest in prevention (even probabilistically) would lead to more denial because it would decrease the likelihood that the agent's biased beliefs are pivotal in leading to an inferior investment decision. ${ }^{22}$

\footnotetext{
${ }^{21}$ Note that the subsidy exclusively impacts on welfare indirectly through its effect on the likelihood that the agent invests in prevention. The subsidy does not enter the agent's utility more directly once its costs in terms of higher taxes are subtracted.

${ }^{22}$ It may still be optimal to force an agent to invest in prevention. This policy is more likely to be welfare improving when risk and loss are very high (so that investing is a good decision on average and the anxiety induced from contracting the disease is high) and the prevention technology is ineffective (so that investing in prevention does not completely eliminate anxiety).
} 


\section{Conclusion}

People in poor countries are often optimistic about health risks and resistant to information. They also tend to underinvest in disease prevention. It is therefore tempting to be pessimistic about the potential of policy interventions to increase people?s preventative efforts. We may think that subsidising prevention will not induce much behavioural change if health risks are underestimated and that misguided beliefs cannot be altered if people resist information. Fortunately, randomised controlled trials in developing countries show that subsidies and incentives are often highly effective at increasing prevention. This paper explains why behaviour (and beliefs) may be surprisingly responsive to incentives. It also shows that, if beliefs are motivated, incentives or subsidies can improve welfare.

My model makes the maximally simple assumption that beliefs are freely chosen. It is plausible that people's ability to self-deceive is more limited than that. Of course, if there are factors impacting on the cognitive costs of self-deception, these will also impact on who self-deceives. Moreover, firms will try to influence cognitive costs to their advantage. A better understanding of how the ability to self-deceive interacts with factors in the environment is thus likely to further improve our understanding of the distribution of optimistic beliefs across different settings and individuals. It might also provide insights into whether certain nutritional supplements and homeopathy, which gave rise to multi-billion dollar industries, function as self-deception aides.

Although economists and psychologists still know very little about the factors that shape the cognitive costs of self-deception, insights are starting to accrue. For example, self-deception seems to require some vagueness or uncertainty surrounding the variable in question (Sloman et al., 2010). For this reason, probabilities, which are inherently noisy and complicated objects, are probably particularly likely to invite the human tendency to self-deceive in pursuit of anticipatory gains. Furthermore, it seems plausible that informative signals make it harder to self-deceive, which could explain why denialists might also exhibit information avoidance. ${ }^{23}$

In the presence of health externalities, one person's utility depends on others' preventative efforts. As a result, groupthink may arise (Bénabou, 2013). How health risk denial forms in groups and how it spreads through social networks is an interesting topic for future theoretical and empirical work. Another promising application of health risk denial is insurance markets. Sandroni and Squintani (2007) study the case of exoge-

\footnotetext{
${ }^{23}$ See Spiegler (2008) for why optimal expectations models do not, without assuming supply side frictions, imply information avoidance.
} 
nously optimistic insurance seekers. However, by setting contractual terms, insurance providers exert some influence over insurance seekers' incentive to become optimistic. As a result, optimism may well be endogenous to the strategic interaction between firms and customers.

\section{References}

Acemoglu, Daron and Joshua Linn, "Market Size in Innovation: Theory and Evidence from the Pharmaceutical Industry," The Quarterly Journal of Economics, 2004, 119 (3), 1049-1090.

Akerlof, George A and William T Dickens, "The Economic Consequences of Cognitive Dissonance," American Economic Review, June 1982, 72 (3), 307-19.

Ashraf, N., J. Berry, and J.M. Shapiro, "Can Higher Prices Stimulate Product Use? Evidence from a Field Experiment in Zambia," American Economic Review, 2010, 100 (5), 2383-2413.

Banerjee, A. and E. Duflo, Poor Economics: A Radical Rethinking of the Way to Fight Global Poverty, Public Affairs, 2011.

Bénabou, Roland, "Groupthink: Collective delusions in organizations and markets," The Review of Economic Studies, 2013, 80 (2), 429-462.

Bénabou, Roland and Jean Tirole, "Self-Confidence and Personal Motivation," The Quarterly Journal of Economics, 2002, 117 (3), pp. 871-915.

Bénabou, Roland and Jean Tirole, "Mindful economics: The production, consumption, and value of beliefs," The Journal of Economic Perspectives, 2016, 30 (3), 141164.

Bridet, Luc and Peter Schwardmann, "Selling dreams: Endogenous overoptimism and collateral use in financial contracts," Mimeo, 2016.

Brunnermeier, Markus K. and Jonathan A. Parker, "Optimal Expectations," American Economic Review, September 2005, 95 (4), 1092-1118.

Brunnermeier, Markus K, Christian Gollier, and Jonathan A Parker, "Optimal Beliefs, Asset Prices, and the Preference for Skewed Returns," The American Economic Review, 2007, 97 (2), 159-165. 
Caplin, Andrew and John Leahy, "Psychological Expected Utility Theory And Anticipatory Feelings," The Quarterly Journal of Economics, February 2001, 116 (1), $55-79$.

- and Kfir Eliaz, "AIDS policy and psychology: a mechanism-design approach.," RAND Journal of Economics, 2003, 34 (4), 631 - 646.

Carrillo, Juan D and Thomas Mariotti, "Strategic ignorance as a self-disciplining device," The Review of Economic Studies, 2000, 67 (3), 529-544.

Cohen, Jessica and Pascaline Dupas, "Free Distribution or Cost-Sharing? Evidence from a Randomized Malaria Prevention Experiment," The Quarterly Journal of Economics, February 2010, 125 (1), 1-45.

Coutts, Alexander, "Testing Models of Belief Bias: An Experiment," Available at SSRN 2647508, 2015.

de la Rosa, Leonidas Enrique, "Overconfidence and moral hazard," Games and Economic Behavior, 2011, 73 (2), 429 - 451.

de Meza, David and Clive Southey, "The Borrower's Curse: Optimism, Finance and Entrepreneurship," Economic Journal, March 1996, 106 (435), 375-86.

Dubois, Pierre, Olivier de Mouzon, Fiona Scott-Morton, and Paul Seabright, "Market size and pharmaceutical innovation," The RAND Journal of Economics, 2015, $46(4), 844-871$.

Duflo, E., P. Dupas, M. Kremer, and S. Sinei, "Education and HIV/AIDS Prevention," World Bank Policy Research Working Paper No. 4024, 2006.

Dunkle, K.L., R.K. Jewkes, H.C. Brown, M. Yoshihama, G.E. Gray, J.A. McIntyre, and S.D. Harlow, "Prevalence and patterns of gender-based violence and revictimization among women attending antenatal clinics in Soweto, South Africa," American Journal of Epidemiology, 2004, 160 (3), 230.

_, _, M. Nduna, J. Levin, N. Jama, N. Khuzwayo, M.P. Koss, and N. Duvvury, "Perpetration of partner violence and HIV risk behaviour among young men in the rural Eastern Cape, South Africa," Aids, 2006, 20 (16), 2107.

Dunning, David, Chip Heath, and Jerry M Suls, "Flawed self-assessment implications for health, education, and the workplace," Psychological science in the public interest, 2004, 5 (3), 69-106. 
Dupas, P., "Health behavior in developing countries," Annu. Rev. Econ., 2011, 3 (1), 425-449.

Eil, D. and J.M. Rao, "The good news-bad news effect: Asymmetric processing of objective information about yourself," American Economic Journal: Microeconomics, 2011, 3 (2), 114-138.

Festinger, Leon, A theory of cognitive dissonance, Vol. 2, Stanford university press, 1962.

Grebe, E. and N. Nattrass, "AIDS Conspiracy Beliefs and Unsafe Sex in Cape Town," AIDS and Behavior, 2011, pp. 1-13.

Green, E.C., D.T. Halperin, V. Nantulya, and J.A. Hogle, "Uganda's HIV prevention success: the role of sexual behavior change and the national response," AIDS and Behavior, 2006, 10 (4), 335-346.

Janz, Nancy K and Marshall H Becker, "The health belief model: A decade later," Health Education 83 Behavior, 1984, 11 (1), 1-47.

Köszegi, Botond, "Health anxiety and patient behavior," Journal of health economics, 2003, 22 (6), 1073-1084.

_ , "Emotional Agency," The Quarterly Journal of Economics, 02 2006, 121 (1), 121155 .

Kocher, Martin G, Michal Krawczyk, and Frans van Winden, "Let me dream on! Anticipatory emotions and preference for timing in lotteries," Journal of Economic Behavior \& Organization, 2014, 98, 29-40.

Kopczuk, Wojciech and Joel Slemrod, "Denial of death and economic behavior," Advances in Theoretical Economics, 2005, 5 (1).

Kremer, M. and E. Miguel, "The illusion of sustainability," The Quarterly Journal of Economics, 2007, 122 (3), 1007-1065.

Kremer, Michael, "Pharmaceuticals and the developing world," The Journal of Economic Perspectives, 2002, 16 (4), 67-90.

Kunda, Ziva, "Motivated inference: Self-serving generation and evaluation of causal theories.," Journal of Personality and Social Psychology, 1987, 53 (4), 636. 
_ , "The case for motivated reasoning.," Psychological bulletin, 1990, 108 (3), 480.

Landier, Augustin and David Thesmar, "Financial Contracting with Optimistic Entrepreneurs," Review of Financial Studies, January 2009, 22 (1), 117-150.

Lazarus, R.S., Stress and emotion: A new synthesis, Springer Publishing Company, 2006.

Mayraz, Guy, "Wishful Thinking," CEP Discussion Papers dp1092, Centre for Economic Performance, LSE November 2011.

Mijović-Prelec, Danica and Drazen Prelec, "Self-deception as self-signalling: a model and experimental evidence," Philosophical Transactions of the Royal Society B: Biological Sciences, 2010, 365 (1538), 227-240.

Miller, John M, Eline L Korenromp, Bernard L Nahlen, and Richard W Steketee, "Estimating the number of insecticide-treated nets required by African households to reach continent-wide malaria coverage targets," Jama, 2007, 297 (20), $2241-2250$.

Mobius, Markus M., Muriel Niederle, Paul Niehaus, and Tanya S. Rosenblat, "Managing Self-Confidence: Theory and Experimental Evidence," NBER Working Papers 17014, National Bureau of Economic Research, Inc May 2011.

Oster, Emily, Ira Shoulson, and E. Ray Dorsey, "Optimal Expectations and Limited Medical Testing: Evidence from Huntington Disease.," American Economic Review, 2013, 103 (2), $804-830$.

Pecoul, Bernard, Pierre Chirac, Patrice Trouiller, and Jacques Pinel, "Access to essential drugs in poor countries: a lost battle?," Jama, 1999, 281 (4), 361-367.

Pettifor, A.E., D.M. Measham, H.V. Rees, and N.S. Padian, "Sexual power and HIV risk, South Africa," Emerging Infectious Diseases, 2004, 10 (11), 1996-2004.

Quattrone, George A and Amos Tversky, "Causal versus diagnostic contingencies: On self-deception and on the voter's illusion.," Journal of Personality and Social Psychology, 1984, 46 (2), 237.

Ringold, Debra Jones, "Boomerang effects in response to public health interventions: some unintended consequences in the alcoholic beverage market," Journal of Consumer Policy, 2002, 25 (1), 27-63. 
Robinson, Thomas $\mathbf{N}$ and Joel D Killen, "Do cigarette warning labels reduce smoking?: paradoxical effects among adolescents," Archives of pediatrics $\&$ adolescent medicine, 1997, 151 (3), 267-272.

Rothschild, Michael and Joseph E Stiglitz, "Equilibrium in Competitive Insurance Markets: An Essay on the Economics of Imperfect Information," The Quarterly Journal of Economics, November 1976, 90 (4), 630-49.

Sandroni, Alvaro and Francesco Squintani, "A Survey on Overconfidence, Insurance and Self-Assessment Training Programs," Unpublished report, 2004.

_ and _, "Overconfidence, Insurance, and Paternalism," The American Economic Review, December 2007, 97 (5), 1994-2004.

Schwardmann, Peter and Joel van der Weele, "Deception and self-deception," Tinbergen Institute Discussion Paper, TI 2016-012/I, 2016.

Sloman, Steven A, Philip M Fernbach, and York Hagmayer, "Self-deception requires vagueness," Cognition, 2010, 115 (2), 268-281.

Spiegler, Ran, "On Two Points of View Regarding Revealed Preferences and Behavioral Economics," in Andrew Caplin and Andrew Schotter, eds., The foundations of positive and normative economics: a handbook, Oxford University Press 2008.

Spinnewijn, Johannes, "Insurance and Perceptions: How to Screen Optimists and Pessimists," The Economic Journal, June 2013, 123 (569), 606-633.

Stockman, Lauren J, Thea K Fischer, Michael Deming, Bagrey Ngwira, Cameron Bowie, Nigel Cunliffe, Joseph Bresee, and Robert E Quick, "Pointof-use water treatment and use among mothers in Malawi," Emerging Infectious Diseases, 2007, 13 (7), 1077-1080.

UNAIDS, Report on the global AIDS epidemic, Joint United Nations Programme on HIV/AIDS., 2008.

UNAIDS/WHO, "AIDS epidemic update," Joint United Nations Programme on HIV/AIDS. 2005.

Walque, D. De, "How does the impact of an HIV/AIDS information campaign vary with educational attainment? Evidence from rural Uganda," Journal of Development Economics, 2007, 84 (2), 686-714. 
Weinstein, Neil D, "Unrealistic optimism about susceptibility to health problems," Journal of behavioral medicine, 1982, 5 (4), 441-460.

_, "Unrealistic optimism about susceptibility to health problems: Conclusions from a community-wide sample," Journal of behavioral medicine, 1987, 10 (5), 481-500.

\section{A Proofs}

\section{Proof of Proposition 1}

Unconstrained maximisation of the agent's $t=1$ objective function, given by (4), with respect to $\tilde{\theta}$ yields the following first order condition

$$
\frac{L\left(\alpha^{2} \theta L-(1-s) \alpha^{2} \tilde{\theta} L-s \bar{c}-s \alpha p\right)}{\bar{c}}=0
$$

Note that the second derivative of (4) with respect to $\tilde{\theta}$ is $\frac{-(1-s) \alpha^{2} L^{2}}{\bar{c}}$, which is negative everywhere given the assumption that $s<1$. Therefore, equation (9) characterises a global maximum. Denote the $\tilde{\theta}$ thats solves (9) by

$$
\tilde{\theta}_{s o l}=\frac{\theta}{1-s}-\frac{s(\bar{c}+\alpha p)}{(1-s) \alpha^{2} L}
$$

If $\tilde{\theta}_{\text {sol }} \leq 0$, then any $\tilde{\theta}_{1}>0$ yields less expected utility than $\tilde{\theta}_{2}=0$. Because the agent cannot believe in negative probabilities, $\tilde{\theta}_{\text {sol }} \leq 0$ implies that the optimal belief is $\tilde{\theta}^{*}=0$. If $\tilde{\theta}_{\text {sol }}>0$, then $\tilde{\theta}^{*}=\tilde{\theta}_{\text {sol }}$. The comparative statics follow from the respective 
first derivatives of $\tilde{\theta}^{*}$. First derivatives are zero for $\tilde{\theta}^{*}=0$. If $\tilde{\theta}^{*}>0$ they are given by
i) $\frac{\partial \tilde{\theta}^{*}}{\partial s}=\frac{\alpha^{2} L \theta-\alpha p-\bar{c}}{(1-s)^{2} \alpha^{2} L}<0$
ii) $\frac{\partial \tilde{\theta}^{*}}{\partial p}=-\frac{s}{(1-s) \alpha L}<0$
iii) $\frac{\partial \tilde{\theta}^{*}}{\partial \bar{c}}=-\frac{s}{(1-s) \alpha^{2} L}<0$
iv) $\frac{\partial \tilde{\theta}^{*}}{\partial \alpha}=\frac{s(\alpha p+2 \bar{c})}{(1-s) \alpha^{3} L}>0$
v) $\frac{\partial \tilde{\theta}^{*}}{\partial L}=\frac{s(\alpha p+\bar{c})}{(1-s) \alpha^{2} L^{2}}>0$
vi) $\frac{\partial \tilde{\theta}^{*}}{\partial \theta}=\frac{1}{(1-s)}>0$

The inequality that establishes result i) is implied by my assumption that, even with realisitc beliefs, investing is not rational in all states of the world, i.e. $\alpha L \theta-p-\bar{c}<0$.

\section{Proof of Proposition 2}

The assumption that $\alpha^{2} \theta L-\alpha p>s \bar{c}$ implies that $D^{d}>0$. Then, the difference between the realist's and the denialist's demand is given by

$$
D^{r}-D^{d}=\frac{s\left(\bar{c}+\alpha p-\theta \alpha^{2} L\right)}{(1-s) \alpha \bar{c}},
$$

which is positive if and only if $\bar{c}+\alpha p>\theta \alpha^{2} L$. I assume that even a realist does not always invest in prevention at $t=2$, i.e. that $\bar{c}>\theta \alpha L-p$. This implies $\bar{c}+\alpha p>\theta \alpha^{2} L$. Therefore, the denialist's demand is always smaller than the realist's. Furthermore, i) $\frac{\partial\left(D^{r}-D^{d}\right)}{\partial p}=\frac{s}{(1-s) \bar{c}}>0$, ii $) \frac{\partial\left(D^{r}-D^{d}\right)}{\partial \bar{c}}=\frac{s(\theta \alpha L-p)}{(1-s) \bar{c}^{2}}>0$, and iii) $\frac{\partial\left(D^{r}-D^{d}\right)}{\partial \alpha}=-\frac{s\left(\theta \alpha^{2} L+\bar{c}\right)}{(1-s) \alpha^{2} \bar{c}}<0$. The inequality in result ii) is implied by the assumption that demand is positive, i.e. $\alpha^{2} \theta L-\alpha p>s \bar{c}$. 


\section{Proof of Proposition 3}

We define and derive the following differences in sensitivities under the assumption of positive demand of the denialist, i.e. $\alpha^{2} \theta L-s \bar{c}-\alpha p>0$ :

$$
\begin{aligned}
& \Delta_{p} \equiv \frac{d D^{d}}{d p}-\frac{d D^{r}}{d p}=-\frac{2-s}{(1-s) \bar{c}} \\
& \Delta_{\bar{c}} \equiv \frac{d D^{d}}{d \bar{c}}-\frac{d D^{r}}{d \bar{c}}=-\frac{s(\alpha \theta L-p)}{(1-s) \bar{c}^{2}} \\
& \Delta_{\alpha} \equiv \frac{d D^{d}}{d \alpha}-\frac{d D^{r}}{d \alpha}=\frac{s\left(\alpha^{2} L \theta+\bar{c}\right)}{\alpha^{2}(1-s) \bar{c}}
\end{aligned}
$$

Since $s<1$, we have that $\Delta_{p}$ and $\Delta_{\bar{c}}$ are negative and that $\Delta_{\alpha}$ is positive.

\section{Proof of Proposition 4}

Suppose $\alpha^{2} \theta L>s \bar{c}$. Then profit is given by

$$
\pi_{m}=p D^{d}(p)=p\left(\frac{\alpha \theta L-p}{(1-s) \bar{c}}-\frac{s}{(1-s) \alpha}\right)
$$

Profit is positive as long as $p<\alpha \theta L-\frac{s \bar{c}}{\alpha}$. Since profit is strictly concave in price, the monopoly price is obtained by setting the first derivative of $\pi_{m}$ w.r.t. p equal to zero. This yields

$$
p_{m}^{*}=\frac{1}{2}\left(\alpha \theta L-\frac{s}{\alpha} \bar{c}\right)
$$

which results in positive profits. $\tilde{\theta}_{m}^{*}$ and $D_{m}^{*}$ are obtained by substituting $p_{m}^{*}$ into $\tilde{\theta}^{*}(p)$ and $D^{d}(p)$ respectively.

\section{Proof of Proposition 5}

We prove that the unique Nash equilibrium gives rise to each firm charging $p=0$. Beliefs and allocations then follow from propositions 1 and 2.

Suppose there are two firms in the market, firm i and firm j. Suppose that firm i charges $p_{i}=0$ and firm $\mathrm{j}$ charges $p_{j}=0$. Then both firms make zero profits. There exists no profitable deviation for firm i. Charging $p_{i}>0$ results in zero demand for its product, and, hence, zero profits. Charging $p_{i}<0$ yields $\pi_{i}<0$ because demand will be positive, but sales are associated with a loss. By symmetry, there also exists no profitable deviation for firm $\mathrm{j}$. Therefore, $p_{i}=p_{j}=0$ is a Nash equilibrium. 
To establish uniqueness, note that if either firm charged $p<0$ and drew any demand, it would make losses and could increase its profits by raising its price. Moreover, $p_{i} \geq$ $p_{j}>0$ is not an equilibrium because firm i could profitably deviate and charge $p_{i}=p_{j}-\epsilon$ and earn

$$
\pi_{i}=\left(p_{j}-\epsilon\right)\left(\frac{\alpha \theta L-p_{j}-\epsilon}{(1-s) \bar{c}}-\frac{s}{(1-s) \alpha}\right)
$$

which, for $\epsilon$ sufficiently small, is positive and larger than the $\pi_{i}=\frac{p_{j}}{2}\left(\frac{\alpha \theta L-p_{j}}{(1-s) \bar{c}}-\frac{s}{(1-s) \alpha}\right)$ that firm i obtains by charging $p_{i}=p_{j}$. Finally, $p_{i}>p_{j}=0$ is not an equilibrium because firm $\mathrm{j}$ could raise its price by a small amount and increase its profits.

\section{Proof of Corollary 1}

To show that $D_{c}^{*}(s=0)-D_{m}^{*}(s=0)>D_{c}^{*}(s>0)-D_{m}^{*}(s>0)$, we simply populate the expressions on both sides of the inequality with the demands derived in propositions 4 and 5.

\section{Proof of Proposition 6}

The monopolist's equilibrium profit and marginal incentive to invest in $\alpha$ are respectively given by

$$
\pi\left(p *_{m}\right)=\frac{\left(\alpha^{2} L \theta-s \bar{c}\right)^{2}}{4(1-s) \alpha^{2} \bar{c}} \quad \text { and } \quad \frac{\partial \pi\left(p *_{m}\right)}{\partial \alpha}=\frac{\left(\alpha^{4} L^{2} \theta^{2}-s^{2} \bar{c}^{2}\right)}{2(1-s) \alpha^{3} \bar{c}}
$$

Since $\operatorname{sign}\left(\frac{\partial \pi\left(p *_{m}\right)}{\partial \alpha}\right)=\operatorname{sign}\left(\alpha^{4} L^{2} \theta^{2}-s^{2} \bar{c}^{2}\right)$, the marginal incentive to invest is positive if and only if $\alpha>\hat{\alpha}=\sqrt{\frac{s \bar{c}}{\theta L}}$. 


\section{Proof of Proposition 7}

When $c$ is not subtracted from the agent's anticipatory utility, the agent chooses her belief to maximize the following concave objective function.

$$
\begin{aligned}
\mathbb{E}_{1}\left[U_{3}-x(c+p) \mid \theta\right]+ & s \mathbb{E}_{1}\left[\mathbb{E}_{2}\left[U_{3} \mid \tilde{\theta}\right]\right]= \\
& \int_{0}^{\alpha \tilde{\theta} L-p}[V-(1-\alpha) \theta L-c-p] \frac{1}{\bar{c}} d c+\int_{\alpha \tilde{\theta} L-p}^{\bar{c}}[V-\theta L] \frac{1}{\bar{c}} d c \\
+ & s\left(\int_{0}^{\alpha \tilde{\theta} L-p}[V-(1-\alpha) \tilde{\theta} L] \frac{1}{\bar{c}} d c+\int_{\alpha \tilde{\theta} L-p}^{\bar{c}}[V-\tilde{\theta} L] \frac{1}{\bar{c}} d c\right)
\end{aligned}
$$

This yields optimal beliefs $\tilde{\theta}^{*}=\max \left[\frac{\theta}{1-s}-\frac{s \bar{c}+s \alpha p}{\left(1-s^{2}\right) \alpha^{2} L}, 0\right]$ and demand

$$
\begin{aligned}
D^{*} & =z \int_{0}^{\alpha \theta^{*} L-p} \frac{1}{\bar{c}} d c \\
& = \begin{cases}\frac{(1+s) \alpha \theta L}{(1-s) \bar{c}}-\frac{s \bar{c}+\alpha p}{(1-s) \alpha \bar{c}} & \text { if }(1+s) \alpha^{2} \theta L>s \bar{c}+\alpha p \\
0 & \text { otherwise }\end{cases}
\end{aligned}
$$

When $D^{*}=0$, then $\frac{\partial D^{*}}{\partial s}=0$. When $D^{*}>0$, the first derivative of $D^{*}$ w.r.t. $s$ is given by

$$
\frac{\partial D^{*}}{\partial s}=\frac{2 \alpha^{2} \theta L-\bar{c}-\alpha p}{(1-s)^{2} \alpha \bar{c}}
$$

which is greater than zero if and only if $2 \alpha^{2} \theta L-\bar{c}-\alpha p>0$

\section{Proof of Proposition 8}

The agent's objective function at $t=1$ is given by

$$
\begin{aligned}
& \mathbb{E}_{1}\left[U_{3} \mid \theta\right]+s \mathbb{E}_{1}\left[\mathbb{E}_{2}\left[U_{3} \mid \tilde{\theta}\right]\right]= \\
& \quad \beta \int_{0}^{\beta \alpha \tilde{\theta} L-p}[V-(1-\alpha) \theta L-c-p] \frac{1}{\bar{c}} d c+\beta \int_{\beta \alpha \tilde{\theta} L-p}^{\bar{c}}[V-\theta L] \frac{1}{\bar{c}} d c \\
& +s\left(\beta \int_{0}^{\beta \alpha \tilde{\theta} L-p}[V-(1-\alpha) \tilde{\theta} L-c-p] \frac{1}{\bar{c}} d c+\beta \int_{\beta \alpha \tilde{\theta} L-p}^{\bar{c}}[V-\tilde{\theta} L] \frac{1}{\bar{c}} d c\right)
\end{aligned}
$$


and is concave if its second derivative w.r.t. $\tilde{\theta}$, given by $-\frac{\beta \alpha^{2} L^{2}(1+s)\left(\beta s^{2}+2 \beta s-2 s+\beta\right)}{\bar{c}}$, is negative. This is the case if and only if

$$
\beta>\frac{2 s}{(1+s)^{2}}
$$

The right side of 11 is increasing in $s$ and so 11 is always satisfied if it is satisfied for the maximum value of $s$, i.e. $s=1$. This is the case if, as I assume, $\beta>0.5$. Function 10 is maximised for

$$
\tilde{\theta}_{\beta}=\frac{\theta}{\beta(1+s)^{2}-2 s}-\frac{s(\bar{c}+\alpha p)}{(1+s)\left(\beta(1+s)^{2}-2 s\right) \beta \alpha^{2} L}
$$

The optimal belief coincides with $\tilde{\theta}_{\beta}$ if $\tilde{\theta}_{\beta}>0$ and, because negative probabilities are not possible, is zero otherwise

\section{Proof of Proposition 9}

For a given policy $(\sigma, T)$, the agent chooses her belief at $t=1$ in order to maximize her $t=2$ utility, given by 8 . If $\alpha^{2} \theta L-\alpha p>s \bar{c}$, so that a denialist sometimes invests in prevention, her optimal belief is therefore given by

$$
\tilde{\theta}^{*}=\frac{\theta}{1-s}-\frac{s(\bar{c}+\alpha(p-\sigma))}{(1-s) \alpha^{2} L}
$$

Optimal beliefs are independent of $T$ and the subsidy acts just like a price reduction.

Substituting the budget balance constraint

$$
T=\int_{0}^{\alpha \tilde{\theta} L-p+\sigma} \sigma \frac{1}{\bar{c}} d c
$$

and optimal beliefs $\tilde{\theta}^{*}$ into the policy maker's objective function, also given by 8 , yields

$$
\begin{aligned}
W= & \int_{0}^{\alpha \tilde{\theta}^{*} L-p+\sigma}[V-(1-\alpha) \theta L-c-p+\sigma] \frac{1}{\bar{c}} d c+\int_{\alpha \tilde{\theta}^{*} L-p+\sigma}^{\bar{c}}[V-\theta L] \frac{1}{\bar{c}} d c \\
& +s\left(\int_{0}^{\alpha \tilde{\theta}^{*} L-p+\sigma}\left[V-(1-\alpha) \tilde{\theta}^{*} L-c-p+\sigma\right] \frac{1}{\bar{c}} d c+\int_{\alpha \tilde{\theta}^{*} L-p+\sigma}^{\bar{c}}\left[V-\tilde{\theta}^{*} L\right] \frac{1}{\bar{c}} d c\right) \\
& -(1+s) \int_{0}^{\alpha \tilde{\theta}^{*} L-p+\sigma} \sigma \frac{1}{\bar{c}} d c
\end{aligned}
$$


Simplifying yields

$$
\begin{aligned}
W= & \int_{0}^{\alpha \tilde{\theta}^{*} L-p+\sigma}[V-(1-\alpha) \theta L-c-p] \frac{1}{\bar{c}} d c+\int_{\alpha \tilde{\theta}^{*} L-p+\sigma}^{\bar{c}}[V-\theta L] \frac{1}{\bar{c}} d c \\
& +s\left(\int_{0}^{\alpha \tilde{\theta}^{*} L-p+\sigma}\left[V-(1-\alpha) \tilde{\theta}^{*} L-c-p\right] \frac{1}{\bar{c}} d c+\int_{\alpha \tilde{\theta}^{*} L-p+\sigma}^{\bar{c}}\left[V-\tilde{\theta}^{*} L\right] \frac{1}{\bar{c}} d c\right)
\end{aligned}
$$

The equilibrium $\sigma$ is the maximand of 14 , i.e.

$$
\sigma^{*}=\frac{s\left(\bar{c}+\alpha p-\alpha^{2} \theta L\right)}{\alpha(1+2 s)},
$$

The equilibrium subsidy $\sigma^{*}$ is strictly positive if $s>0$ because $\bar{c}+\alpha p>\alpha^{2} \theta L$. This inequality is implied by $\bar{c}+p>\alpha \theta L$, which I assumed to rule out the uninteresting case in which a rational agent invests in all states of the world.

The equilibrium tax and belief are obtained by substituting $\sigma^{*}$ into 12 and 13 and solving the system of equations.

\section{B HIV/AIDS denial is caused by an inability to act}

In the context of a large generalised HIV epidemic, being in denial about some of the risks and costs associated with HIV/AIDS may constitute an important psychological coping mechanism and help reduce anxiety. The model emphasises that such denial may come at the cost of impaired sexual decision making, since an overly optimistic individual may fail to protect herself when the risk of infection does in fact warrant taking protective measures. This cost, however, may be low for groups who lack autonomy in sexual decision making. A lack of empowerment on behalf of women in many African countries, in particular, may therefore help explain gender differences in HIV knowledge and risk attitudes.

In terms of the model, a lack of empowerment or autonomy in sexual decision making may be reflected in a high cost of protecting oneself, i.e. a high $\bar{c}$. Alternatively, the risk of potentially being undermined by one's partner may be reflected in a low $\alpha$. A low $\alpha$ may also represent situations in which a woman may protect herself in all of her voluntary sexual encounters, but cannot avoid the threat of being raped. That this threat is real and prevalent in some contexts is reflected in South African estimates that, based on interviews with women attending antenatal clinics, place the prevalence of physical/sexual partner violence as high as 55.5\% (Dunkle et al., 2004). 
Green et al. (2006) find that the social, economic and legal empowerment of women played a crucial role in Uganda's strategy to combat HIV/AIDS, which is widely considered to be one of the few successful HIV prevention campaigns in Africa. In particular, they highlight the role of giving women more political voice, the strengthening of rape and defilement laws and the allocation of property rights to women.

In a South African sample, 10.5 percent of African women compared to 1.71 percent of African men believe that "HIV is harmless and does not cause AIDS" (Grebe and Nattrass, 2011). Men, on the other hand, are more likely than women to agree with the statement that "AIDS was created by American scientists". The stark difference in the distribution of AIDS denialist beliefs compared to AIDS conspiracy theorist beliefs points to motivated beliefs resulting from low empowerment, since other variables such as educational attainment should have a negative effect on both kinds of beliefs. The fact that female empowerment is low in South Africa is reflected in the high incidence of partner violence against women. This has implications for sexual outcomes, as young men who perpetrate partner violence engage in significantly higher levels of HIV risk behavior than non-perpetrators (Dunkle et al., 2006) and women with low relationship control are 2.1 times more likely to use condoms inconsistently (Pettifor et al., 2004).

Education is likely to play an important role in empowering women. In a field experiment in Kenya, Duflo et al. (2006) find that reducing the cost of education leads more girls to be "confident that they can say no if their partner wants to have sex" and to realise that "when one has HIV, one eventually dies". Training teachers to teach the national AIDS curriculum or encouraging students to discuss condom use had no effect on these perceptions, which indicates that it may be the empowerment that is associated with education rather than the provision of information that shifts attitudes.

In a Ugandan sample, De Walque (2007) shows that the reduction in seroconversion following a HIV information campaign is increasing in educational attainment. This result is driven exclusively by women being more receptive to HIV information when they are more educated. Since it is plausible that empowerment through education is greater for women than for men, but somewhat less plausible that education affects men and women's information processing or cognitive abilities differently, this evidence lends further support to the model's predictions in the realm of HIV/AIDS.

It is possible that the mechanisms highlighted above contribute to a gender gap in HIV knowledge that is observable in country-level data. According to UNAIDS/WHO (2005), young men in a sample drawn from 35 countries in sub-Saharan were $20 \%$ more likely to have correct knowledge about HIV than young women.

Figure 4 a exhibits the positive relationship (significant at the 5 percent level) between 


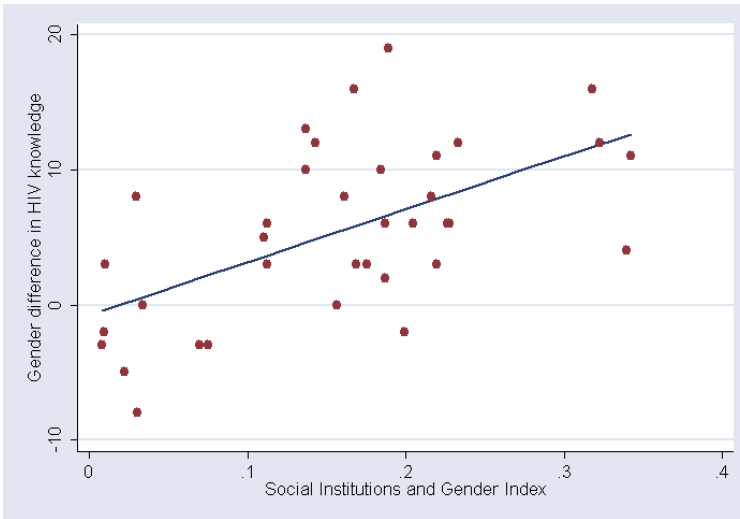

(a)

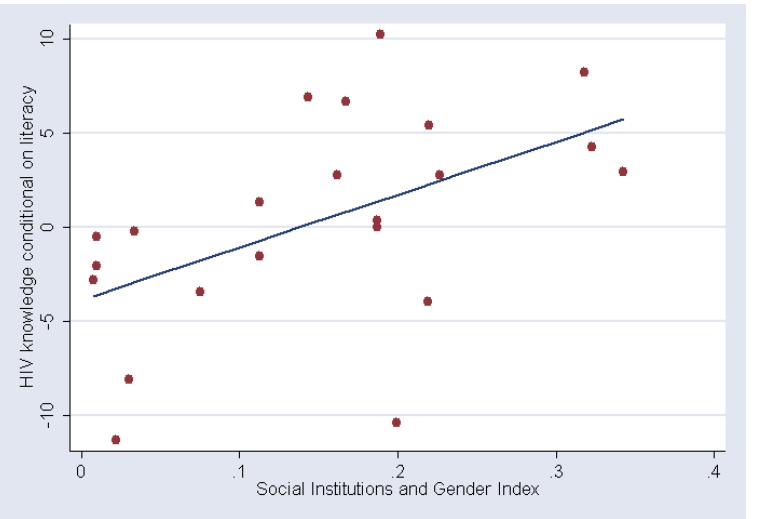

(b)

Figure 4 The correlation between gender differences in HIV knowledge on the SIGI. a) unconditional correlation, for 38 countries, b) correlation conditional on gender difference in adult literacy for 22 countries,

the gender gap in HIV knowledge and the social institutions and gender index (SIGI) for a sample of 38 countries. The HIV knowledge variable ${ }^{24}$ measures the percentage of young people aged 15 to 24 who both correctly identify ways of preventing the sexual transmission of HIV and reject major misconceptions about HIV transmission. The SIGI 25 measures social and institutional inputs to gender inequality such as laws prohibiting and punishing violence against women, women's ownership rights, dress codes in public, the acceptability of polygamy and genital mutilation, and freedom of movement. The index takes a higher value for greater gender inequality.

It may be argued that gender inequality impacts on HIV knowledge exclusively through differences in education. Figure $4 \mathrm{~b}$ shows that a positive relationship (significant at the 10 percent level) between gender differences in HIV knowledge and female empowerment persists once we make the gender gap in HIV knowledge conditional on a country's gender gap in literacy rates. The notion that low female autonomy incentivizes denial is one candidate explanation for this finding. Another explanation may be that learning information pertaining to HIV requires freedom of movement and interactions with peers, which are undermined by social norms that discriminate against women.

\footnotetext{
${ }^{24}$ Estimates derived from household surveys (DHS, MICS) are presented here, as compiled and reported by UNAIDS in the 2008 Report on the Global AIDS epidemics, Annex 2 UNAIDS (2008).

${ }^{25}$ Obtained from OECD's Gender, Institutions and Development Database (2009). Available on the web: http://stats.oecd.org/Index.aspx?DataSetCode=GID2
} 


\section{Experienced anxiety}

Lazarus (2006) cautions scholars of emotion that "separating emotion from coping does a disservice to the integrity and complexity of the emotion process, which at any turn considers how we might cope" (p. 37). The model imposes structure on how we can think about the interrelationship between anxiety, cognitive coping, i.e. denial, and behavioural coping, i.e. investing in prevention and thus predicts the level of anxiety the agent ultimately experiences.

Surveys on health attitudes frequently elicit how worried respondents are about contracting a certain disease. The theoretical counterpart of this survey item is given by

$$
\mathcal{A}=s\left[\int_{0}^{\alpha \tilde{\theta}^{*} L-p}\left((1-\alpha) \tilde{\theta}^{*} L+c+p\right) \frac{1}{\bar{c}} d c+\int_{\alpha \tilde{\theta}^{*} L-p}^{\bar{c}} \tilde{\theta}^{*} L \frac{1}{\bar{c}} d c\right]
$$

which captures the dread an agent of innate anxiety $s$ feels anticipating the expected physical loss $L$.

Consider the two effects on experienced anxiety of an increase in, for example, the expected cost $\bar{c} / 2$. First, investment in prevention decreases, which increases the threat of infection and, hence, experienced anxiety. Second, $\tilde{\theta}^{*}$ decreases by proposition 1 , which in turn reduces experienced anxiety. It is easy to show that the second effect dominates. $^{26}$

Proposition 10. Experienced anxiety $\mathcal{A}$ is weakly decreasing in price $p$ and the expected investment cost $\bar{c} / 2$, i.e. $\frac{\partial \mathcal{A}}{\partial p} \leq 0$ and $\frac{\partial \mathcal{A}}{\partial \bar{c}} \leq 0$. The effect of an increase in the prevention technology's effectiveness $\alpha$ on experienced anxiety is ambiguous.

Proof. When $\alpha^{2} \theta L \leq s \bar{c}+\alpha p$, then $\tilde{\theta}^{*}=0, \mathcal{A}=0$ and $\frac{\partial \mathcal{A}}{\partial \bar{c}}=\frac{\partial \mathcal{A}}{\partial p}=\frac{\partial \mathcal{A}}{\partial \alpha}=0$. Now consider the case of $\alpha^{2} \theta L>s \bar{c}+\alpha p$.

The effect of a change in $\bar{c}$ is given by

$$
\frac{\partial \mathcal{A}}{\partial \bar{c}}=\frac{s\left(\alpha^{2} \theta L-\left(2 s-s^{2}\right) \bar{c}-\left(2 s-s^{2}\right) \alpha p\right)}{\left(1-s^{2}\right) \alpha^{2}}
$$

\footnotetext{
${ }^{26}$ Implicit in the baseline model is the assumption that anxiety increases in the expected consumption loss implied by having to pay $c+p$ with positive probability. Proposition 10 is robust to relaxing this assumption, which I do in section 5.1.
} 
Therefore, $\frac{\partial \mathcal{A}}{\partial \bar{c}}<0$ if and only if $\alpha^{2} \theta L-\left(2 s-s^{2}\right) \bar{c}-\left(2 s-s^{2}\right) \alpha p<0$, i.e. if and only if

$$
\alpha \theta L-\frac{\left(2 s-s^{2}\right) \bar{c}}{\alpha}-\left(2 s-s^{2}\right) p<0
$$

Since I assume that $\alpha \theta L-\bar{c}-p<0$, inequality 15 is satisfied.

The effect of a change in $p$ is given by

$$
\frac{\partial \mathcal{A}}{\partial p}=\frac{s\left(\alpha^{2} \theta L-\left(2 s-s^{2}\right) \bar{c}-\alpha p\right)}{\left(1-s^{2}\right) \alpha},
$$

which is negative, because $\alpha \theta L-\bar{c}-p<0$.

The effect of a change in $\alpha$ is given by

$$
\frac{\partial \mathcal{A}}{\partial \alpha}=-\frac{s\left(\alpha^{3} \theta L(\alpha \theta L-p)-\bar{c}\left(2 s-s^{2}\right)(\alpha p+\bar{c})\right)}{\left(1-s^{2}\right) \alpha^{3}}
$$

This derivative may be negative, e.g. when $s$ is small, or positive, e.g. when $s$ is large.

This suggests that elevated levels of experienced anxiety might be more prevalent in rich country settings, where $p$ and $\bar{c}$ relative to income are low. It is in these settings that the physical payoffs warrant remaining realistic, even if this comes at the cost of worrying.

\section{Price sensitivities}

Several factors may depress the demand for preventative health care in poor settings. Here, I study how three of the most plausible of such factors impact on the agent's sensitivity of demand. I denote the (exogenous) optimist by superscript $o$. She is characterised by belief $\theta^{o} \in(0, \theta)$ with $\frac{\partial \theta^{\circ}}{\partial z}=0$ for all $z \in\{p, \bar{c}, \alpha\}$. Her demand for health care is given by

$$
D^{o}=\int_{0}^{\alpha \theta^{\circ} L-p} \frac{1}{\bar{c}} d c
$$

An impatient individual discounts $t=3$ health outcomes when she decides whether or not to invest in health care at $t=2$. She has a discount rate $\delta \in(0,1)$ and invests in 
prevention whenever $\delta \alpha \theta L>c$. Her ex ante demand is given by

$$
D^{\delta}=\int_{0}^{\delta \alpha \theta L-p} \frac{1}{\bar{c}} d c
$$

Finally, a liquidity constraint individual can only invest in prevention for cost realisations such that $c+p<m$ and $m$ is so small that she cannot always make worthwhile investments, i.e. $m<\alpha \theta L-p$. Her demand is

$$
D^{m}=\int_{0}^{m-p} \frac{1}{\bar{c}} d c
$$

The corresponding sensitivities of demand in a variable $z$ are are simply the first derivatives in $z$. The following proposition highlights the difference between the sensitivity of a realist's demand in factors of the environment in comparison to that of other agents.

Proposition 11. Suppose that $\alpha^{2} \theta L>s \bar{c}$, so that an individual who engages in denial sometimes invests in prevention. Then the realist's demand for preventative health care is weakly more sensitive to changes in the environment than the demand of an exogenously optimistic, an impatient or a liquidity constrained individual. Specifically,

$$
\begin{aligned}
\text { i) } \frac{d D^{r}}{d p} & =\frac{d D^{o}}{d p}=\frac{d D^{\delta}}{d p}=\frac{d D^{m}}{d p} \\
\text { ii) } \frac{d D^{r}}{d \bar{c}} & <\frac{d D^{o}}{d \bar{c}}, \frac{d D^{\delta}}{d \bar{c}}, \frac{d D^{m}}{d \bar{c}} \\
\text { iii) } \frac{d D^{r}}{d \alpha} & >\frac{d D^{o}}{d \alpha}, \frac{d D^{\delta}}{d \alpha}<\frac{d D^{m}}{d \alpha}
\end{aligned}
$$

Proof. To prove the proposition, we simply calculate the relevant first derivatives and find that

$$
\begin{aligned}
\text { i) } \frac{d D^{r}}{d p} & =\frac{d D^{o}}{d p}=\frac{d D^{\delta}}{d p}=\frac{d D^{m}}{d p}=-\frac{1}{\bar{c}} \\
\text { ii) } \frac{d D^{r}}{d \bar{c}} & =-\frac{\alpha \theta L-p}{\bar{c}^{2}}<\frac{d D^{o}}{d \bar{c}}=-\frac{\alpha \theta^{o} L-p}{\bar{c}^{2}}, \frac{d D^{\delta}}{d \bar{c}}=-\frac{\delta \alpha \theta L-p}{\bar{c}^{2}}, \frac{d D^{m}}{d \bar{c}}=-\frac{m-p}{\bar{c}^{2}} \\
\text { iii) } \frac{d D^{r}}{d \alpha} & =\frac{\alpha \theta L}{\bar{c}}>\frac{d D^{o}}{d \alpha}=\frac{\alpha \theta^{o} L}{\bar{c}}, \frac{d D^{\delta}}{d \alpha}=\frac{\delta \alpha \theta L}{\bar{c}}<\frac{d D^{m}}{d \alpha}=0
\end{aligned}
$$

The inequality in result $i i$ holds, because $\alpha \theta^{\circ} L, \delta \alpha \theta L$ and $m$ are each smaller than $\alpha \theta L$. The inequalities in result $i i i$ hold because $\theta^{\circ}$ and $\delta \theta$ are smaller than $\theta$, but greater than zero.

In combination with proposition 3, proposition 11 implies that the sensitivity of 
demand may be a good metric to distinguish motivated beliefs from other depressants of demand. Motivated beliefs, but not other depressants of demand, generally imply a higher sensitivity of demand to changes in the environment. 